Division

Chemical Technology

Division

Chemical Technology

Division

Chemical Technology

Division

Chemical Technology

Division

Chemical Technology

Division

Chemical Technology

Division

Chemical Technology

Division

Chemical Technology

Division

Chemical Technology

Division

Chemical Technology

Division

Chemical Technology

Division

Chemical Technology

Division

Chemical Technology

Division

\section{AN INTRODUCTION TO PYROCHEMISTRY WITH EMPHASIS ON NUCLEAR APPLICATIONS}

by Irving Johnson

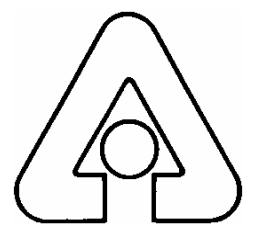

Argonne National Laboratory, Argonne, Illinois 60439

operated by The University of Chicago

for the United States Department of Energy under Contract W-31-109-Eng-38

Chemical Technology

Division

Chemical Technology

Division

Chemical Technology

Division

Chemical Technology

Division 
Argonne National Laboratory, with facilities in the states of Illinois and Idaho, is owned by the United States Government and operated by The University of Chicago under the provisions of a contract with the Department of Energy.

\footnotetext{
DISCLAIMER

This report was prepared as an account of work sponsored by an agency of the United States Government. Neither the United States Government nor any agency thereof, nor The University of Chicago, nor any of their employees or officers, makes any warranty, express or implied, or assumes any legal liability or responsibility for the accuracy, completeness, or usefulness of any information, apparatus, product, or process disclosed, or represents that its use would not infringe privately owned rights. Reference herein to any specific commercial product, process, or service by trade name, trademark, manufacturer, or otherwise, does not necessarily constitute or imply its endorsement, recommendation, or favoring by the United States Government or any agency thereof. The views and opinions of document authors expressed herein do not necessarily state or reflect those of the United States Government or any agency thereof, Argonne National Laboratory, or The University of Chicago.
}

Available electronically at http://www.doe.gov/bridge

Available for a processing fee to U.S. Department of Energy and its contractors, in paper, from:

U.S. Department of Energy

Office of Scientific and Technical Information

P.O. Box 62

Oak Ridge, TN 37831-0062

phone: (865) 576-8401

fax: (865) 576-5728 


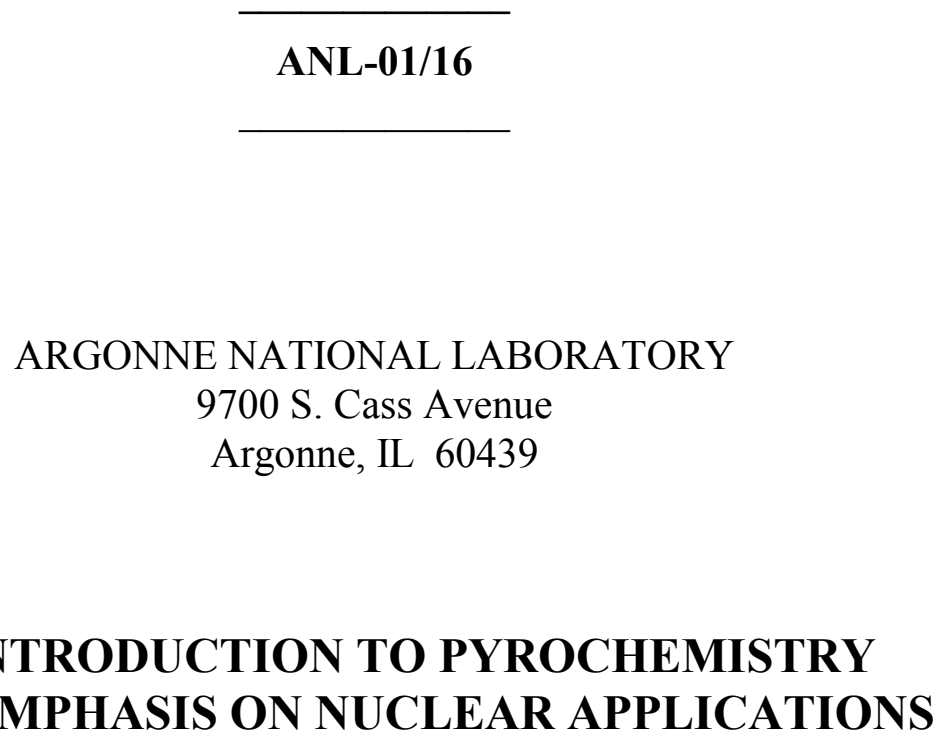

by

Irving Johnson

Chemical Technology Division

June 2001 



\section{TABLE OF CONTENTS}

ABSTRACT 1

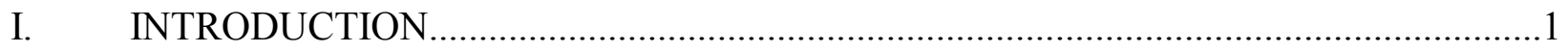

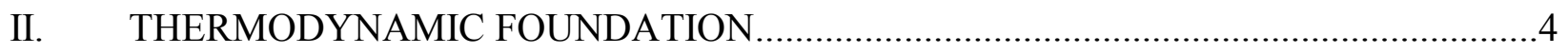

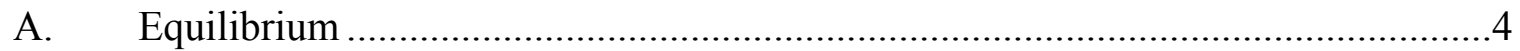

B. Gibbs (Free) Energy, Enthalpy, and Entropy …………………………………....

C. Gibbs (Free) Energy Change and Reaction............................................................. 6

D. Gibbs Energy and Equilibrium Constant ...........................................................

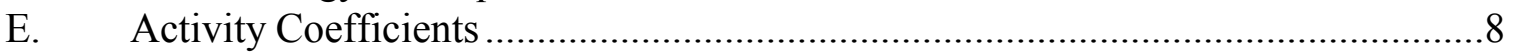

III. DISTRIBUTION BETWEEN LIQUID METAL AND MOLTEN

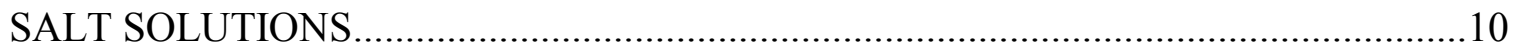

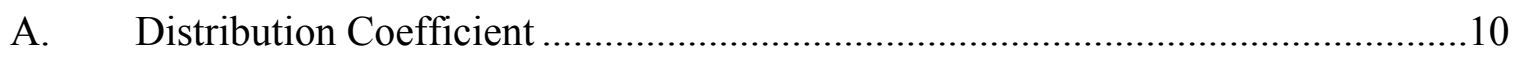

B. Estimation of Gibbs Energy of Super-cooled Salts................................................12

C. Computation of Distribution Coefficient for U/Pu Partition ....................................13

D. Separation of Americium from Plutonium ………………………………..........14

E. Distribution between Liquid $\mathrm{Mg}-\mathrm{Zn}$ and Molten $\mathrm{MgCl}_{2}$ Solutions ......................20

F. Activity Coefficients in Liquid Metal Solutions ...................................................23

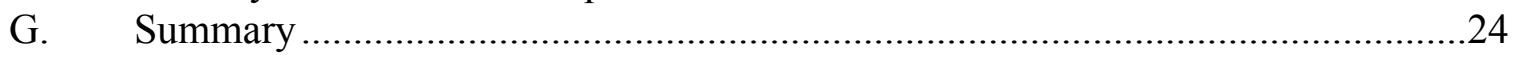

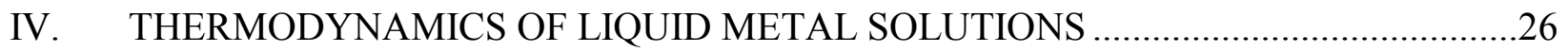

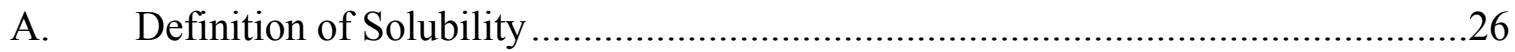

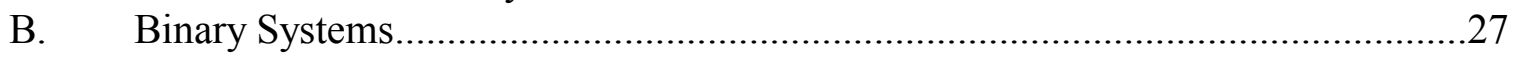

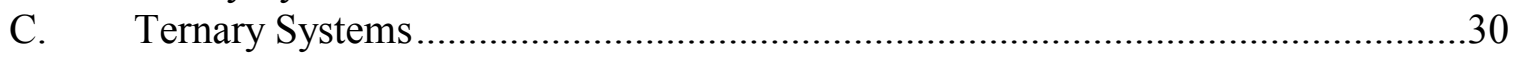

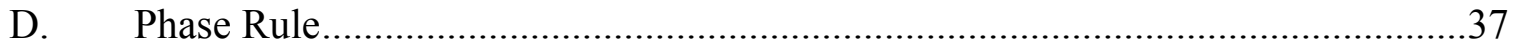

E. Effects of Co-precipitation.............................................................................

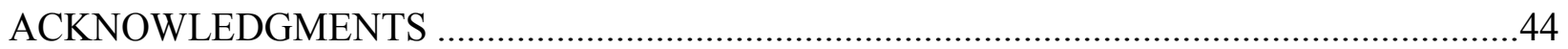




\title{
AN INTRODUCTION TO PYROCHEMISTRY WITH EMPHASIS ON NUCLEAR APPLICATIONS
}

\author{
Irving Johnson
}

\begin{abstract}
This report illustrates the application of thermodynamic principles to further understanding of pyrochemical processes useful for the recovery and purification of nuclear materials. It draws extensively upon the theoretical and experimental work conducted over nearly four decades in the Chemical Technology Division (formerly called the Chemical Engineering Division) of Argonne National Laboratory. After a brief discussion of fundamental thermodynamic principles and equations, they are applied to the relative distribution of actinides and other elements in molten salts and liquid metal solutions and to solubilities in liquid metal solutions.
\end{abstract}

\section{INTRODUCTION}

This report is an introduction to the physical chemical foundations for the theoretical methods that have been developed to assist in the development of pyrochemical processes for nuclear materials. These methods have been developed over a period of about four decades. Almost all of the main concepts were in place by the middle sixties, although a few new applications have been made during the last decade. The early work was part of the research to develop processes for fast reactors at the ANL Chemical Engineering (CEN) Division, since renamed the Chemical Technology (CMT) Division. The CEN (now CMT) Division had the responsibility to develop compact processes for the out-of-pile part of the fuel cycle for a fast reactor.

The initial work led to the development of a "melt refining" process that was used to demonstrate the feasibility of on-site reprocessing of the metallic fuel used for Experimental Breeder Reactor-II (EBR-II). Until the early nineties, the research was mainly directed to fast reactor fuel cycles. Currently, the emphasis is on the development of processes to treat nuclear wastes. Pyrochemical studies in CEN/CMT have not been continuous over the last four decades. There have been periods when the work was not being actively pursued because of a lack of funding for nuclear reactor research. It is hoped that this report will preserve the main ideas that have been developed so that, when nuclear reactors are again being built and advanced designs are being developed in the United States, the foundations for the development of the pyrochemical processes will be readily available. This report is part of the heritage that this author's generation is passing on to future generations. 
All of the pyrochemical processes that have been developed to date have as their objective the separation of two or more elements. Separation processes are based on distributing the elements that are to be separated between phases that can be physically separated. For example, metallic iron can be produced from iron oxide ore by reacting the ore with carbon (originally charcoal, later coke) at high temperatures to form liquid metallic iron and either $\mathrm{CO}_{2}$ or CO. The other impurities in the iron oxide ore are collected in a molten oxide slag. In this case the iron is collected as one liquid phase, the "impurities" as another liquid phase, and the oxygen as gaseous $\mathrm{CO}$ and $\mathrm{CO}_{2}$. In practice, a good separation of the liquid iron from the molten slag can be achieved, but the clean separation of the slag from the liquid iron is not easy. The result is that the slag contains small amounts of metallic iron. This is more or less typical of phase separations. It is often possible to separate one phase cleanly from the other, but only if some of the primary phase remains with the second phase. For example, in phase separations routinely performed using "separatory" funnels in a physical chemistry laboratory, it is difficult to drain the lower liquid phase (often the aqueous phase) from the upper liquid phase (often an organic phase). Not only is it difficult to close the stopcock when the last drop of water has drained out, but the inside of the funnel is often coated with water.

Examples of phase separations closer to our recent pyrochemical experience include the melt refining and electrorefining processes developed at CEN/CMT for the treatment of spent nuclear fuel. The melt refining process involved melting the spent metallic EBR-II fuel in a zirconia crucible. In practice, $\mathrm{ZrO}_{2}$ reacted with the more active fission products to form their oxides and sub-stoichiometric zirconia. These reaction products formed a dross on the surface of the molten $U$ alloy. The molten $U$ alloy was poured off, leaving behind the dross. But it was not possible to pour off all of the liquid $U$ alloy because some of the alloy was trapped with the dross. These "heels" (referred to as "skulls") contained all of the more active fission products (and some of the $\mathrm{Pu}$ that had been generated in the fuel, which was a ${ }^{235} \mathrm{U}$-enriched alloy), as well as several percent of the uranium and the associated noble metal fission products. Fortunately, the noble metal fission product-uranium alloy was an excellent fast reactor fuel. The small amount lost with the heels allowed the fuel composition to be stabilized. Subsequently, a pyrochemical process was developed in CEN/CMT to recover the ${ }^{235} \mathrm{U}$ and Pu from the heels, the "skull reclamation process." It was never put into operation because the EBR-II reactor was changed to an irradiation facility. Nevertheless the practical experience obtained in the development of the skull reclamation process was valuable to the development of other pyrochemical processes.

The electrorefining process also can be used to illustrate phase separation problems. In this process, solid metallic uranium is electrodeposited from a molten salt electrolyte on a cathode. This cathode is removed from the molten salt electrolyte, and the solid uranium is mechanically removed. A small amount of the salt adheres to the metallic uranium, which then must be removed. In the initial process schemes, melting of the uranium product allowed the molten salt to collect on the melt surface. After freezing, the salt could be mechanically removed from the uranium ingot.

The development of pyrochemical processes involves the selection of the chemical reactions that lead to the differences in the distribution between two or more phases and the 
devising of the "mechanical" methods for the separation of the phases. We will be mostly concerned with the chemical reaction aspect of process development. This is not meant to imply that the mechanics of phase separations are less important, only that this author's interest has been in the "chemistry."

In the sections that follow (1) the thermodynamic foundation will be reviewed, (2) the chemistry of separations based on distribution between liquid metallic solutions and molten salts will be explained, and (3) the physical chemistry of liquid metallic solutions will be developed. All of the chemistry is based on equilibrium thermodynamics. In a few cases the implications of nonequilibrium will be discussed. Because pyrochemical processes operate at high temperatures, the rates of the main chemical reactions have seldom been of major importance as far as the separations are concerned. However, the high temperatures lead to materials-of-construction problems, where equilibrium thermodynamics often can help. 


\section{THERMODYNAMIC FOUNDATION}

This section discusses the thermodynamic relations that are used in the remaining sections. This is not a systematic development of thermodynamics, but more like a refresher of the equations that once were well known but may have been forgotten due to lack of use. This will avoid the need to explain these equations each time they are used in the following sections. I assume that anyone reading this report has studied some physical chemistry, and so most of the concepts introduced are familiar. Nevertheless, I have not hesitated to state elementary concepts or definitions since it has been my experience that, sometimes, misunderstandings can be traced to lack of remembrance of the "simple." It is intended that all of the equations introduced in this section can be used by the reader without extensive further study.

\section{A. Equilibrium}

Contrary to common sense, most chemical reactions that are used in practical processes do not go to completion in one direction. Rather the reaction proceeds part way to completion, and a mixture of reactants and products is obtained when all reaction has appeared to have stopped. Early in our study of chemistry we learn that, when this state is reached, reaction has not stopped, but the rate of reaction of reactants to form products has become equal to the rate of the back reaction of products to form reactants. This is defined as a state of equilibrium. We are taught that the ratio of concentrations of products to reactants is constant. Thus, for the reaction,

$$
n_{A} A+n_{B} B=n_{C} C+n_{D} D
$$

there is an equilibrium relation:

$$
\frac{x_{C}^{n_{C}} \times x_{D}^{n_{D}}}{x_{A}^{n_{A}} \times x_{B}^{n_{B}}}=K_{e q}
$$

where the x's are "concentrations," and the n's are moles that are reacting. Note that the products are in the numerator, while the reactants are in the denominator, a more or less universal convention. We also are taught that, for many reactions, this relation is only approximately valid. Since this relation will be used over and over again, we need to investigate why this relation is only approximate, and what changes are needed to make it exact. This is a very useful relation, and we are reluctant to abandon it. To learn what we need to do it is necessary to dig deeper into the source of this relation. This involves the derivation of this relation from thermodynamic concepts. Methods for the computation of the "equilibrium constant," as well as corrections that can be applied to the concentrations, will be discussed.

\section{B. Gibbs (Free) Energy, Enthalpy, and Entropy}

For our purposes we recall the definition of the Gibbs (free) energy function:

$$
\Delta G=\Delta H-T \Delta S
$$


where $G$ is the Gibbs (free) energy (Gibbs, $c a$ 1875), $H$, the enthalpy; $S$, the entropy; and $T$, the absolute temperature. This basic equation expresses our common experience with chemical reactions. The $\Delta H$ term expresses the insight that energy is conserved in any reaction (the first law of thermodynamics). The second term expresses experience with spontaneous reactions (the second law of thermodynamics), i.e., the fact that heat goes from hot to cold, that gases form a homogeneous mixture if brought together, that ice melts if heated above the freezing point of water, and so forth.

The quantities $G, H$, and $S$ are known as state functions. By "state" we mean the temperature, pressure, volume, quantity, and composition of the system. The change in the values of state functions is only dependent on the change in state, and not the way in which the system goes from one state to another; this is referred to as "path independent." Values of $\Delta G$ and $\Delta H$ are defined in terms of values in some standard state (whose absolute numerical values are not knowable). The third law of thermodynamics permits absolute values of the entropy to be determined. Therefore, $\Delta G$ and $\Delta H$ are only known relative to some assumed standard state for the substance. Such values are usually written as $\Delta_{f} G^{o}$ and $\Delta_{f} H^{o}$, where according to recent convention the $f$ is placed as a subscript between the $\Delta$ and the $G$ or $H$. The $f$ stands for "formation," the terms being referred to as the standard Gibbs (free) energy or enthalpy of formation. This is the value you will find in the tables of selected values, usually as $\mathrm{kcal} / \mathrm{mol}$ or more recently, $\mathrm{kJ} / \mathrm{mol}$. The standard state will be indicated in this report by a superscript ${ }^{\circ}$. The International Union of Pure and Applied Chemistry (IUPAC) has set as a standard notation a circle with a line through it as the correct superscript for the standard state. This symbol is tedious to insert using a word processor, and so ${ }^{\circ}$ will be used here. The standard Gibbs energy and enthalpy of formation of the pure elements in their standard states are defined as equal to zero. The value of $\Delta_{f} S^{o}$ must be computed from the values (absolute) for the elements that make up the compound, for example, for $\mathrm{UCl}_{3}(\mathrm{~s})$ :

$$
\Delta_{f} S_{U C l_{3}}^{o}=S_{U C l_{3}}^{o}-S_{U}^{o}-\frac{3}{2} S_{C l_{2}}^{o}
$$

While it is common practice to refer to the exchange of heat or energy between systems as if heat or energy were "things," this is not correct. The Gibbs energy (sometimes also called

\footnotetext{
${ }^{1}$ There is a relation between the temperature, pressure, and volume known as the equation of state, so that if any two are known, the third can be calculated. We usually omit dependencies on gravitational and magnetic fields, as well as surface energy effects.

${ }^{2}$ Many compilations of data give the values of these thermodynamic functions for a pressure of $0.1 \mathrm{MPa}$ (about one atmosphere) and $298.15 \mathrm{~K}$.

${ }^{3}$ The entropy can be shown to be equal to $\mathrm{R} \times \ln \mathrm{W}$, where $\mathrm{R}$ is the gas constant and $\mathrm{W}$ is the number of configurations available for the system. When $\mathrm{W}$ is unity, the entropy is zero. The third law of thermodynamics implies that for most pure substances the number of configurations available approaches unity at the zero of the absolute temperature, and hence, the entropy approaches zero. This allows the absolute entropy of many substances to be experimentally measured.

${ }^{4}$ One calorie equals 4.184 joules.

${ }^{5}$ Absolute entropies are experimentally determined by measurement of the heat necessary to raise the temperature of the substance, i.e., the specific heat, beginning at temperatures as close to absolute zero as feasible. The change in entropy is determined, but in this case since the value at absolute zero is believed to be zero, the absolute values at higher temperatures can be obtained.
} 
"free energy"), the enthalpy, and the entropy are thermodynamic properties of the system, variables that have values but do not represent a "thing." The confusion about "heat" liberated during chemical reactions led to at least a century of floundering before the first law of thermodynamics was correctly stated.

\section{Gibbs (Free) Energy Change and Reaction}

The great utility of the Gibbs energy is that its sign and numerical value can be used to predict the direction and extent of a chemical reaction. If the $\Delta_{r} G$ for a reaction is positive, then the reaction is not spontaneous in the direction as written; if negative, the reaction is spontaneous; and if zero, the system is in equilibrium (equally "spontaneous" in both directions). Consider the reaction

$$
U_{C l}(c)+P u(c)=P u C l_{3}(c)+U(c)
$$

At $298.15 \mathrm{~K}$, the standard Gibbs energy change, $\Delta_{r} G^{o}$, for this reaction is

$$
\begin{aligned}
& \Delta_{r} G^{o}=\Delta_{f} G^{o}\left(P u C l_{3}\right)+\Delta_{f} G^{o}(U)-\Delta_{f} G^{o}\left(U C l_{3}\right)-\Delta_{f} G^{o}(P u) \\
& \Delta_{r} G^{o}=-213.296+0.0-(-189.910+0.0) \\
& \Delta_{r} G^{o}=-23.386
\end{aligned}
$$

where the values are in $\mathrm{kcal} / \mathrm{mol}{ }^{6}$ This means that when the reactants and products are in their standard states, the reaction is spontaneous as written. Note that the Gibbs energies of formation of the elements in their standard states are zero.

The enthalpy change for this reaction would be obtained in the same way and is found to be equal to

$$
-229.8+0.00-(-206.0+0.0)=-23.8 \mathrm{kcal} / \mathrm{mol}
$$

The standard entropy change, $\Delta_{r} S^{o}$, is also computed in the same way, except now the standard entropies of the pure elements are not zero:

$$
\begin{aligned}
& \Delta_{r} S^{o}=S^{0}\left(\mathrm{PuCl}_{3}\right)+S^{0}(U)-S^{o}\left(U C l_{3}\right)-S^{o}(P u) \\
& \Delta_{r} S^{o}=38.000+12.00-38.000-13.420 \\
& \Delta_{r} S^{o}=-1.42
\end{aligned}
$$

where the result is in cal $/ \mathrm{K}$. The equal entropy values for the two chlorides and the five-figure accuracy are questionable. Note that $T \Delta_{r} S^{0}=-0.423 \mathrm{kcal}$ at $298 \mathrm{~K}$, so that $\Delta_{r} H^{o}-T \Delta_{r} S^{o}=-23.4$, as found above for $\Delta_{r} G^{o}$. The standard Gibbs energy change for this reaction at $1000 \mathrm{~K}$ can be

\footnotetext{
${ }^{6}$ These values are taken from L. B. Pankratz, Thermodynamic Properties of Halides, Bulletin 674, U.S. Bureau of Mines (1984).
} 
approximately computed from Eq. 2-3 if it is assumed that the enthalpy and the entropy of formation are independent of temperature. Using this approximation, one obtains $-22.4 \mathrm{kcal}$ for the standard Gibbs energy change at $1000 \mathrm{~K}$. From the Pankratz tables one computes $-20.5 \mathrm{kcal}$. The difference is within the uncertainties of these data.

\section{Gibbs Energy and Equilibrium Constant}

Another reason we are interested in the standard Gibbs energy change is that it can be used to calculate the equilibrium constant for a reaction. But, to make this connection we need to relate the Gibbs energy of a substance in a solution phase to its concentration. The solution to this problem was devised by G. N. Lewis in 1907, when he invented two new functions, the activity and the activity coefficient. By comparing reactions in the gas phase to reactions involving liquid (or solid) solutions, Lewis defined the activity, $a_{i}$, of a substance in a solution by the relation:

$$
\Delta_{f} G_{i}(s o l)=\Delta_{f} G_{i}^{o}+R T \ln a_{i}
$$

where $\Delta_{f} G_{i}(\mathrm{sol})$ is the Gibbs energy of formation of the substance in the solution, and its activity is $a_{i}$. Often, $\Delta_{f} G_{i}($ sol $)$ is written $\Delta \bar{G}_{i}$, the partial molar Gibbs energy of component $i$ in the solution. This is also known as the chemical potential $\mu_{\mathrm{i}}$. If we use this relation to compute the Gibbs energy change for the reaction in Eq. 2-1, where it is assumed that all of the reactants and products form a solution, then we obtain the following:

$$
\begin{aligned}
& \Delta_{r} G=n_{C} \Delta_{f} G_{C}(\mathrm{sol})+n_{D} \Delta_{f} G_{D}(\mathrm{sol})-n_{A} \Delta_{f} G_{A}(\mathrm{sol})-n_{B} \Delta_{f} G_{B}(\mathrm{sol}) \\
& \Delta_{r} G=n_{C}\left(\Delta_{f} G_{C}{ }^{o}+R T \ln a_{C}\right)+\Lambda-n_{B}\left(\Delta_{f} G_{B}{ }^{o}+R T \ln a_{B}\right) \\
& \Delta_{r} G=\Delta_{r} G^{0}+n_{C} R T \ln a_{C}+\Lambda-n_{B} R T \ln a_{B} \\
& \Delta_{r} G=\Delta_{r} G^{o}+R T \ln \frac{a_{C}^{n_{C}} \times a_{D}^{n_{D}}}{a_{A}^{n_{A}} \times a_{B}^{n_{B}}}
\end{aligned}
$$

where $\Delta_{r} G$ is the Gibbs energy of the reaction with reactants and products in solution, and $\Delta_{r} G^{o}$ is the standard Gibbs energy change for the reaction (reactants and products in their standard states). When the system is in equilibrium, $\Delta_{r} G=0$, and

$$
\begin{aligned}
& \Delta_{r} G^{o}=-R T \ln \frac{a_{C}^{n_{C}} \times a_{D}^{n_{D}}}{a_{A}^{n_{A}} \times a_{B}^{n_{B}}} \\
& \Delta_{r} G^{o}=-R T \ln K_{a}
\end{aligned}
$$

where $K_{a}$ is the activity equilibrium constant, which is sometimes called the "thermodynamic equilibrium constant." It has the same form as the ordinary concentration equilibrium constant if the concentrations are replaced by activities. This is an exact equation. When the correct values 
for the activities are used, the same value of the equilibrium constant is obtained for all experimental equilibrium combinations of the reactants for a given reaction.

\section{E. Activity Coefficients}

The second contribution of G. N. Lewis was to define a factor that when multiplied by the concentration $\left(x_{I}\right)$ yielded the activity $\left(a_{i}\right)$ :

$$
a_{i}=x_{i} \times \gamma_{i}
$$

where $\gamma_{i}$ is the activity coefficient. At first glance, this does not seem as any improvement since an unknown activity is being replaced by an unknown activity coefficient. But recall that for many reactions the concentration equilibrium is nearly independent of concentration, so only small corrections must be made to account for the deviations from simple concentration dependence. Lewis showed that if the solutions were ideal, then the activity coefficients were unity. Hence, the activity coefficient is a measure of the deviation of the solution from ideal or Raoultian behavior. The activity coefficients can be experimentally measured apart from the reaction equilibrium study. Thus, activity coefficients can be measured for solutions that are used in many different reactions. The dependence of activity coefficients on solution composition is one of the "details" that will be important in much of what follows.

One of the prickly problems when using activities and activity coefficients is the question of the standard state. The standard state is the state where the activity is unity, or perhaps a better way of putting this is to say that, when the constituent of a solution is in its standard state, its activity is unity. This follows directly from Eq. 2-8 when we set $\Delta_{f} G(\mathrm{sol})=\Delta_{f} G^{o}$. The confusion arises because different standard states are used for different types of solutions and different units of "concentration," i.e., mole fraction, molality, or molarity (not to mention weight percent, parts per million, and atom percent!). In the following sections we will use as the standard state for the constituents of the solvent, the pure substance in the state of the solution phase (liquid or solid) and mole fractions when convenient. The standard state for the solutes will be either the pure substance in the state that it exists at the temperature of the experiment, or in the state of the solution. We will almost always use the second choice for molten salt solutions and the first choice for metals dissolved in liquid metal solutions. Furthermore, even though the equilibrium solid phase in the case of a metallic solution is an intermetallic compound, we will still use the pure metal (most often solid) as the standard state. Since activities are relative quantities, these choices of standard states do not make our equations inexact. But care is required in the computation of the standard Gibbs energy change for a reaction, so that the standard states are consistent with the states used for the computation of the activities.

One result of our choice for the standard state in liquid metal solutions is that the activity coefficients will have values that reflect the fact that the Gibbs energy of fusion of the metal is usually included. For example, at $500^{\circ} \mathrm{C}$ the solubility of solid uranium (the equilibrium phase) in

\footnotetext{
${ }^{7}$ This somewhat unconventional use is a result of early experimental studies at CEN/CMT, where we determined activities in liquid metal solution with respect to the pure metals. We early adapted the point of view that the conventions used for aqueous or molten salt solutions were not especially useful for liquid metal solutions.
} 
liquid cadmium is about 0.013 mole fraction. If, as adapted in this work, pure solid uranium is the standard state, then the uranium in solution at the solubility mole fraction is in equilibrium with uranium in its standard state, and therefore, its activity is unity. The activity coefficient is then the reciprocal of the solubility, or 76.9. If super-cooled liquid uranium were selected as the standard state, then the Gibbs energy of fusion of the uranium must be estimated and used to calculate the Gibbs energy change of transferring a mole of uranium from the liquid state to the saturated solution. The Gibbs energy of fusion of uranium at $500^{\circ} \mathrm{C}$ is about $985 \mathrm{cal} / \mathrm{mol} .^{-}$(This is positive since the fusion is not spontaneous below the melting point.) When this energy is combined with the solubility, we obtain an activity coefficient of 40.5 . Thus, approximately half of the activity coefficient obtained using solid uranium as the standard state is related, in this example, to the Gibbs energy of fusion. When discussing the solubility of uranium in liquid metals, we will deal with the cases where the equilibrium solid is an intermetallic compound.

Before leaving this topic of standard or reference states, we will briefly discuss some details regarding the computation of the activity coefficient. Assume that a solid substance $A$ is in equilibrium with a liquid saturated solution, where the mole fraction is $x_{A}$. The equilibrium relations are

$$
\begin{aligned}
& A(c)=A(s o l) \\
& \Delta_{r} G=\Delta_{f} G_{A}(s o l)-\Delta_{f} G_{A}(c)=0 \\
& \Delta_{r} G=\Delta_{f} G_{A}{ }^{o}(s o l)+R T \ln a_{A}-\Delta_{f} G_{A}{ }^{o}(c)
\end{aligned}
$$

Two cases arise, whether the standard state for $A$ in the solution is taken as the pure solid or as the super-cooled liquid. If the solid standard state is assumed, then the two Gibbs energies of formation are equal and $R T \ln a_{A}=0$, and $\gamma_{\mathrm{A}}=1 / x_{A}$. On the other hand, if the standard state in the liquid solution is the super-cooled liquid $A$, then the two Gibbs energies are not equal, and their difference is the Gibbs energy of fusion $\left(\Delta_{m} G_{A}\right)$ at temperature $T$. Under these conditions, the activity coefficient of $A$ in the saturated solution is given by the relation:

$$
\gamma_{A}=\frac{1}{x_{A}^{\text {sat'd }}} \times \exp \left(\frac{-\Delta_{m} G_{A}}{R T}\right)
$$

In both cases these activity coefficients are exact only for the saturated solution. If the solutions are dilute, it is often assumed that the activity coefficients are constant (Henry's Law). The measurement of the solubility yields the value of the activity coefficient at only one concentration, the saturated solution.

\footnotetext{
${ }^{8}$ Allan E. Martin, I. Johnson, and H. M. Feder, Trans Met. Soc. AIME 221, 789 (1961).

${ }^{9}$ We calculated the Gibbs energy of fusion from the heat of fusion and the melting point, using the values given by Pankratz in Thermodynamic Properties of Elements and Oxides, Bulletin 672, U.S. Bureau of Mines (1982). It was assumed that the enthalpy and entropy of fusion were independent of temperature.
} 


\section{DISTRIBUTION BETWEEN LIQUID METAL AND MOLTEN SALT SOLUTIONS}

A very large number of the pyrochemical processes that have been developed depend on partition between liquid metal and molten salt solutions. These partition reactions involve two or more solutes in different oxidation states, and are oxidation-reduction reactions. The reduced

forms are usually ${ }^{10}$ dissolved in the liquid metal solution while the oxidized forms are dissolved in the molten salt solution. Oxidation-reduction reactions involve a transfer of electrons, so some species lose electrons (are oxidized) and some species gain electrons (are reduced). Usually, these two species are different, although "disproportionation" reactions are known. Hence, most often some substance is oxidized, and some other substance is reduced. Separations are achieved when the extents of the redox reaction of different substances are different.

\section{A. Distribution Coefficient}

The distribution of a substance, usually a metallic element (i.e., a cation in the molten salt), is expressed in terms of the distribution coefficient, which is defined as the ratio of the mole fraction of the element dissolved in the molten salt solution to the atom fraction dissolved in the liquid metal solution. Note that only the amount in solution in the two phases is involved in this definition. While we will most often use mole fractions to measure the "concentrations," be more convenient to use other measures from time to time.

Various symbols have been used for the distribution coefficient. Jim Knighton in his extensive compilation 12 of experimental data used " $D$ " for the ratio when mole percents and atom percents were used (same values as when mole and atom fractions are used), and "K(D)" when weight percents were used. He probably would have used $\mathrm{K}_{\mathrm{D}}$ if it had been easy to type in those pre-word processor days. We will use $D_{M}$ for the mole-fraction distribution coefficient, where $M$ is the element being partitioned.

To simplify the development of the distribution coefficient equations, a specific reaction will be used. This reaction is the equilibrium between $\mathrm{U}$ and $\mathrm{Pu}$ when a molten chloride salt and a liquid metal solvent are involved:

$$
U C_{3}(\text { salt })+P u(\text { liq metal })=P u C l_{3}(\text { salt })+U(\text { liq metal })
$$

where "salt" means dissolved in the molten salt, and "liq metal" means dissolved in the liquid metal. From Eq. 2-10 and 3-1, we can write:

\footnotetext{
${ }^{10}$ Sometimes two oxidation states can exist in the same molten salt solution.

${ }^{11}$ Strictly speaking, mole fractions are not concentrations, i.e., amount per unit volume, but are more convenient to use since the density of the solution is not needed. The ratio of mole percents is equal to the mole-fraction ratio.

${ }^{12}$ James B. Knighton and K. Nishhio, Compilation of Data on the Distribution of Elements between Fused Salts and Liquid Alloys, Argonne National Laboratory ANL-RCV-4025-Rev (January 1967). Knighton had a metallurgy background, hence the use of the term "alloys."
} 


$$
\frac{a_{U(M)} \times a_{P u C l_{3}}}{a_{P u(M)} \times a_{U C l_{3}}}=K_{a}
$$

where the $a$ 's are activities; $K_{a}$, the thermodynamic equilibrium constant; and $M$, some liquid solvent metal (when present). The distribution coefficients for $\mathrm{U}$ and $\mathrm{Pu}$ can be derived from this relation by the introduction of the activity coefficients:

$$
\frac{x_{U(M)}}{x_{U C l_{3}}} \times \frac{x_{P u C l_{3}}}{x_{P u(M)}}=K_{a} \times \frac{\gamma_{U C l_{3}}}{\gamma_{P u C l_{3}}} \times \frac{\gamma_{P u(M)}}{\gamma_{U(M)}}
$$

or using the definitions of distribution coefficients:

$$
\frac{D_{P u}}{D_{U}}=K_{a} \times \frac{\gamma_{U C l_{3}}}{\gamma_{P u C l_{3}}} \times \frac{\gamma_{P u(M)}}{\gamma_{U(M)}}
$$

Thus, the distribution coefficient for plutonium is proportional to the distribution coefficient for uranium, and the proportionality constant is the product of three factors. The first factor is the thermodynamic equilibrium constant, the second is the ratio of activity coefficients in the molten salt, while the third is the ratio of activity coefficients in the liquid metal. The first factor depends on the Gibbs energy change for the reaction, can be calculated from the standard Gibbs energies of formation, and does not depend on the properties of either the molten salt or the liquid metal solutions. The second factor depends only on the thermodynamic properties of the molten salt solution. It is independent of the properties of the liquid metal solution. The third factor depends only on the thermodynamic properties of the liquid metal solution. Thus, we have divided the computation of the proportionality constant into the calculation of three factors that are independent of each other: a Gibbs energy factor, a molten salt factor, and a liquid metal factor. For this simple example, we require six values: two Gibbs energies of formation, two activity coefficients in the molten salt, and two activity coefficients in the liquid metal.

The thermodynamic equilibrium constant is computed from the Gibbs energies of formation of liquid (super-cooled if necessary) $\mathrm{UCl}_{3}$ and $\mathrm{PuCl}_{3}$ :

$$
K_{a}=\exp \left(\frac{-\left(\Delta_{f} G^{o}\left(P u C l_{3}, l i q\right)-\Delta_{f} G^{o}\left(U C l_{3}, l i q\right)\right)}{R T}\right)
$$

The $\mathrm{Pu}$ and $\mathrm{U}$ are assumed to be in their standard states, and the standard Gibbs energies are zero by definition. It is important that this standard state be the same as will be used for the activity coefficients. To compute the thermodynamic equilibrium constant, we must use the standard Gibbs energies of formation for the two chlorides as liquids. Since for a temperature of $500^{\circ} \mathrm{C}$ both chlorides are solid, the Gibbs energies of the super-cooled salts must be estimated. The Gibbs energy values given in Pankratz are for the solid or liquid compounds in their normal 
range of temperatures. Therefore, we will make a short detour to discuss the estimation of the Gibbs energy of formation of super-cooled salts.

\section{B. Estimation of Gibbs Energy of Super-cooled Salts}

The Gibbs energy of formation for the super-cooled salts is obtained by adding the Gibbs energy of fusion to the Gibbs energy of formation of the solid for the reaction:

$$
\begin{aligned}
& U(c)+3 / 2 \mathrm{Cl}_{2}(g)=\mathrm{UCl}_{3}(\mathrm{c}) \\
& U C l_{3}(c)=\mathrm{UCl}_{3}(\mathrm{liq})
\end{aligned}
$$

The Gibbs energy of fusion may be calculated from the heat and entropy of fusion:

$$
\Delta_{m} G=\Delta_{m} H-T \Delta_{m} S
$$

where $\Delta_{m} S=\Delta_{m} H / T_{m}$. A possibly more accurate estimate can be made if the change in heat capacity, $\Delta_{m} C_{p}$, is known and assumed to be constant. In that case the Gibbs energy of fusion (melting) is represented by a three-term equation of the form:

$$
\Delta_{m} G=a-\Delta_{m} C_{p} T \ln T+b T
$$

where the two constants $a$ and $b$ are determined from the heat of fusion and the melting point (where $\Delta_{m} G=0$ ). Unfortunately, it is not possible to experimentally measure the Gibbsenergy of fusion of super-cooled (or super-heated) salts, so all of these estimates are hypothetical. ${ }^{13}$ In many cases the melting point and heat of fusion are either not known or of questionable accuracy. The same method must be used for computing the Gibbs energy of the liquid salt for the distribution coefficient and the activity coefficient. It might actually be better if the solid salt were used as the standard state for both computations. However, the activity coefficient data are historically based on the liquid salt (super-cooled if necessary) as the standard state.

The following general equation holds for the Gibbs energy of formation of the supercooled liquid salt:

$$
\Delta_{f} G_{\text {liquid }}^{o}=\Delta_{f} G^{o}+\Delta_{m} G
$$

where $\Delta_{m} G$, the Gibbs energy of fusion, is computed by either of the two methods described earlier. It has been found convenient to use this relation to compute values for the Gibbs energy of formation for a range that covers the temperatures usually used in these processes and fits the temperature dependence to a linear equation. The accuracy of the experimental data seldom justifies a more complicated equation.

\footnotetext{
${ }^{13}$ There has been some discussion of the extrapolation of the heat capacity of liquids below their freezing point. See "Workshop at Schloß Ringberg, February 21, to March 3, 1995," Calphad 19, 449 (1995).
} 


\section{Computation of Distribution Coefficient for U/Pu Partition}

After this brief detour, we will continue the computation of the distribution coefficient for $\mathrm{U}$ and $\mathrm{Pu}$ between a liquid metal and a molten salt. The Gibbs energy term is computed from the equations for the Gibbs energies of formation of the molten salts:

$$
\begin{aligned}
& \Delta_{r} G=(-213,171+38.0 T)-(-193,659+40.413 T) \\
& \Delta_{r} G=-19,512-2.413 T
\end{aligned}
$$

At $773.15 \mathrm{~K}, \Delta_{r} G$ is $-21,378 \mathrm{cal} / \mathrm{mol}$, which leads to an activity equilibrium constant of $1.10 \mathrm{x}$ $10^{6}$. This reflects the value of the ratio of the distribution coefficients of $\mathrm{Pu}$ to $\mathrm{U}$ if the activity coefficients are assumed to be unity, i.e., ideal solutions. Thus, under these conditions the reaction would go to completion, and essentially no metallic $\mathrm{Pu}$ would be present if any $\mathrm{UCl}_{3}$ remains in the molten salt. This condition exists in the electrotransport of uranium from a U-Pu alloy to a solid $\mathrm{U}$ cathode. In this case the activity coefficients of $\mathrm{PuCl}_{3}$ and $\mathrm{UCl}_{3}$ in the molten salt are not unity; but since their values are approximately equal, their ratios are approximately unity, as are the activity coefficients of $\mathrm{Pu}$ and $\mathrm{U}$ in the solid alloy.

However, when both the $\mathrm{U}$ and $\mathrm{Pu}$ are dissolved in a low-melting liquid metal, the activity coefficient ratio may be very large or small. In the case $\mathrm{gf}$ liquid $\mathrm{Cd}$ solutions, because the activity coefficients of both $U$ and Pu have been measured, 14 the influence of their ratio on the distribution coefficients can be computed. At $500^{\circ} \mathrm{C}$ the activity coefficients of $\mathrm{Pu}$ and $\mathrm{U}$ in liquid $\mathrm{Cd}$ are $1.39 \times 10^{-4}$ and 74.6 (at zero actinide mole fraction), respectively. Hence, the activity coefficient ratio is $1.86 \times 10^{-6}$, which when multiplied by the thermodynamic equilibrium constant yields a distribution coefficient ratio of 2.05. This is equal to the separation factor for $\mathrm{Pu}$ from $U$ when equilibrium has been established between molten salt and a liquid cadmium solution, if the salt activity coefficient ratio is neglected or set equal to one. This computed value agrees quite well with the experimental value of 1.9 reported by Koyama et al. ${ }^{\text {L5 }}$

The above computation left out the ratio of the activity coefficients of $\mathrm{PuCl}_{3}$ and $\mathrm{UCl}_{3}$ in the molten salt (the $\mathrm{KCl}-\mathrm{LiCl}$ eutectic mixture), since the two activity coefficients have nearly equal values, and therefore, their ratio is about one. The experimental data that are available for these two activity coefficients $\frac{16}{}$ yield a ratio of about 0.88 , which when multiplied by the above ratio of 2.05 yields a separation factor of 1.8 .

This example yields remarkable agreement between the computed and experimental result. This accuracy is better than can be expected, since relatively small changes in the Gibbs

\footnotetext{
${ }^{14}$ Uranium: I. Johnson and H. M. Feder, Trans. Met. Soc. AIME, 224, 468 (1962). Plutonium: I. Johnson, M. G. Chasanov, and R. M. Yonco, Trans. Met. Soc. AIME, 233, 1408 (1965).

${ }^{15}$ T. Koyama, T. R. Johnson, and D. F. Fisher, J. Alloys \& Compounds 189, 34 (1992). In this report the distribution data from a variety of sources were collected.

${ }^{16}$ Uranium chloride : L. Yang, R. G. Hudson, and C.-Y. Chien, Physical Chemistry of Process Metallurgy, Vol. 2, G. R. St Pierre, Editor, Interscience Publishers, New York, pp. 925-943 (1961). Plutonium chloride: G. M. Campbell and J. A. Leary, Thermodynamic Properties of Pu Compounds from EMF Measurements: 1. Pu versus Ag in LiClKCl Eutectic, Los Alamos Report LA-3399 (March 1966).
} 
energy values can lead to large changes in the separation factor. For example, an uncertainty of $\pm 2,000 \mathrm{cal} / \mathrm{mol}$ in the Gibbs energy of formation (which is relatively "good" Gibbs energy data) would lead to a range of values for the separation between about 0.3 to 3.8 times the computed value. This sensitivity to Gibbs energy values arises from the exponential relation between activities (mole fractions) and the Gibbs energies.

As a further illustration of this method of analysis of experimental data, the results for the partition of $\mathrm{Np}, \mathrm{Pu}, \mathrm{Ce}$, and $\mathrm{Nd}$ between liquid $\mathrm{Cd}$ and the $\mathrm{LiCl}-\mathrm{KCl}$ eutectic reported by Koyama et al. ${ }^{15}$ may be considered (An = actinide):

\begin{tabular}{|c|c|c|c|c|c|}
\hline System & $K_{a}$ & $\gamma_{\mathrm{An}} / \gamma_{\mathrm{U}}$ & $\gamma_{\mathrm{UC13}} / \gamma_{\mathrm{AnCl3}}$ & $\mathrm{D}_{\mathrm{An}} / \mathrm{D}_{\mathrm{U}}$ (calc.) & Obs. value \\
\hline $\mathrm{Np} / \mathrm{U}$ & $2.45 \times 10^{4}$ & $1.10 \times 10^{-4}$ & {$[1.0]$} & 2.69 & $2.12 \pm 0.4$ \\
\hline $\mathrm{Pu} / \mathrm{U}$ & $1.11 \times 10^{6}$ & $1.81 \times 10^{-6}$ & 0.88 & 1.81 & $1.88 \pm 0.09$ \\
\hline $\mathrm{Ce} / \mathrm{U}$ & $3.08 \times 10^{11}$ & $1.32 \times 10^{-10}$ & {$[1.0]$} & 40.8 & $45 \pm 6$ \\
\hline $\mathrm{Nd} / \mathrm{U}$ & $8.66 \times 10^{10}$ & $2.41 \times 10^{-10}$ & 3.2 & 38.4 & $39 \pm 6$ \\
\hline
\end{tabular}

In this table the values for the activity coefficient ratios for the salts, when not known, have been set equal to one. The agreement between the computed and observed values is excellent. The salt used for the above computations was the $\mathrm{LiCl}-\mathrm{KCl}$ eutectic mixture, while the salt used for the experiments was the eutectic mixture to which had been added some $\mathrm{NaCl}$, $\mathrm{BaCl}_{2}$, and $\mathrm{CaCl}_{2}$. The salt activity coefficient ratio should thus be slightly different for the two salts. Also worth noting is that there is a limit to the range of distribution coefficients that can be experimentally measured, because of the limitations of analytical sensitivity and the ability to sample the two phases without interphase contamination. Thus, only values between about 1000 and 0.001 can be experimentally determined.

The data in this table illustrate another characteristic of partition between molten salt and liquid metal solutions. The large differences in the values of the separation factors $(\mathrm{SF}=$ $\mathrm{D}_{\mathrm{M} 1} / \mathrm{D}_{\mathrm{M} 2}$ ) computed from the activity equilibrium constant alone are greatly reduced when the liquid-metal activity coefficient ratio is included. The extent of this leveling effect depends on the specific solvent metals. Trends observed when different B group metals are used can be exploited to increase the separation factors.

\section{Separation of Americium from Plutonium}

Molten salt extraction ("MSE") has become the preferred method for the removal of Am from $\mathrm{Pu}$. In this method the $\mathrm{Am}$ is removed by oxidation into a molten salt from liquid $\mathrm{Pu}$. Various oxidizing agents have been used, including $\mathrm{MgCl}_{2}, \mathrm{PuCl}_{3}, \mathrm{Cs}_{2} \mathrm{PuCl}_{6}$, and even $\mathrm{PuO}_{2}$. A variety of molten salt mixtures have also been used, such as molten alkali and alkaline earth chlorides and their mixtures, since the efficiency of the removal depends on the molten salt composition. All of these variants of the MSE process can be understood by consideration of the same equilibria involving the reaction of $\mathrm{PuCl}_{3}$ with $\mathrm{Am}$. The subject of this section is the 
dependence of the partition on salt composition based on the existence of two oxidation states of Am in the molten salt.

Analysis of the MSE data reported by Mullins etgl. 17 indicates that two oxidation states, $\mathrm{Am}^{3+}$ and $\mathrm{Am}^{2+}$, are involved. These authors suggested $\frac{18}{18}$ that only divalent Am was involved, but a subsequent analysis showed that both valence states are important. We will show here that the dependence of the partition of Am on the salt composition is due to differences in the dependence of the thermodynamic activity coefficients of $\mathrm{AmCl}_{3}, \mathrm{AmCl}_{2}$, and $\mathrm{PuCl}_{3}$ on the molten saltcomposition. (Americium dichloride has been prepared and its crystal structure

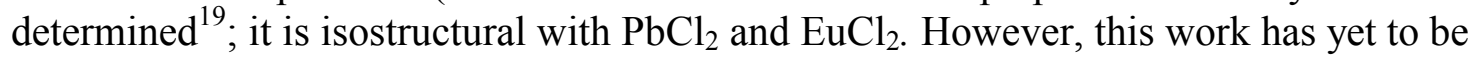
confirmed.)

The extraction of Am from liquid Pu can be described by the two equilibria:

$$
\begin{aligned}
& A m(\text { liq Pu })+\mathrm{PuCl}_{3}(\text { salt })=\mathrm{AmCl}_{3}(\text { salt })+P u(\text { liq Pu }) \\
& 3 \mathrm{Am}(\text { liq Pu })+2 \mathrm{PuCl}_{3}(\text { salt })=3 \mathrm{AmCl}_{2}(\text { salt })+2 \mathrm{Pu}(\text { liq Pu })
\end{aligned}
$$

For these two equilibria, the following equilibrium relations can be written:

$$
\begin{aligned}
& \frac{a_{\mathrm{AmCl}_{3}} a_{\mathrm{Pu}}}{a_{\mathrm{Am}} a_{\mathrm{PuCl}}}=K_{3 a} \\
& \frac{a_{\mathrm{AmCl} l_{2}}^{3} a_{P u}^{2}}{a_{\mathrm{Am}}^{3} a_{\mathrm{PuCl}}^{2}}=K_{2 a}
\end{aligned}
$$

where the two equilibrium constants are for the reactions involving the two oxidation states of Am in the molten salt. From these equations, two mole-fraction equilibrium relations can be derived, where the equilibrium constants now include the activity coefficient ratios. The two mole-fraction equilibrium "constants" are given by the following two equations:

$$
\begin{aligned}
& K_{3 x}=K_{3 a} \times \frac{\gamma_{\mathrm{Am}} \gamma_{\mathrm{PuCl}_{3}}}{\gamma_{\mathrm{Pu}} \gamma_{\mathrm{AmCl}_{3}}} \\
& K_{2 x}=K_{2 a} \times \frac{\gamma_{\mathrm{Am}}^{3} \gamma_{\mathrm{PuCl}_{3}}^{2}}{\gamma_{\mathrm{Pu}}^{2} \gamma_{\mathrm{AmCl}}^{3}}
\end{aligned}
$$

\footnotetext{
${ }^{17}$ L. J. Mullins, A. J. Beaumont, and J. A. Leary, J. Inorg. Nucl. Chem. 30, 147 (1968).

${ }^{18}$ J. A. Leary and L. J. Mullins, J. Chem. Thermodyn. 6, 103 (1974).

${ }^{19}$ R. D. Baybarz, J. Inorg. Nucl. Chem. 35, 483 (1973).
} 
Numerical computations could be completed in an iterative procedure, as follows. Estimated values for the various activity coefficients are used with the $K_{a}$ values to compute $K_{x}$ values, which are then used in the mole-fraction equilibrium relations to obtain the mole fractions. These mole fractions ( $x$ 's) are then used to compute new values for the activity coefficients, and the computation of the $x$ 's is repeated. This procedure is repeated until convergence of the $x$ values occurs. For the present discussion, it is convenient to combine Eqs. 3-13 and 3-14 into the following relation:

$$
D_{A m}=\left\langle K_{3 x} \times D_{P u}\right\rangle+\left\langle K_{2 x}^{1 / 3} \times D_{P u}^{2 / 3}\right\rangle
$$

This equation is obtained by solving the two mole-fraction equilibrium relations for the mole fractions of $\mathrm{AmCl}_{3}$ and $\mathrm{AmCl}_{2}$ and adding them to obtain the total mole fraction of Am in the molten salt solution. While the two mole-fraction equilibrium constants are functions of the molten salt composition, their variation is small for a given salt mixture. As a result, the dependence of $D_{A m}$ on $D_{P u}$ can be studied. The first term on the right side of Eq. 3-17 is proportional to the trivalent Am in the molten salt, while the second term is proportional to the fraction of divalent Am in the molten salt. The analysis of the experimental data is aided by a preliminary assessment of the two equilibrium constants.

The $K_{a}$ values can be computed from the Gibbs energies of formation for the three liquid salts. The values for $\mathrm{PuCl}_{3}$ and $\mathrm{AmCl}_{3}$ are reasonably well known, but depend on estimates of the absolute entropies, specific heats, and heats of fusion. The value for the Gibbs energy of formation of $\mathrm{AmCl}_{2}$ is very uncertain, being based on an estimate of the enthalpy of formation by Morss ${ }^{20}$ and the entropy, heat capacity, and heat of fusion by the present author. ${ }^{2}$ At $850^{\circ} \mathrm{C}, K_{3 a}$ is 34.3 , and $K_{2 a}$ is $2.82 \times 10^{5}\left(K_{2 a}^{1 / 3}\right.$ is 65.6). If the dependence on the activity coefficients is neglected, then at $D_{P u}=0.1$, the two terms in Eq. 3-17 equal 3.43 and 30.4, respectively. In other words, almost $90 \%$ of the Am is in the divalent state.

The value of $\gamma_{P u}$ is close to unity for these liquid $\mathrm{Pu}$ solutions, which are almost pure $\mathrm{Pu}$ (the Am content is usually no greater than a few percent). The value of $\gamma_{A m}$ is not known but is expected to be constant (Henry's law) over the small concentration range of these solutions. Examination of the Am-Pu phase diagram ${ }^{22}$ suggests small deviations from ideal behavior; hence, the activity coefficient may be assumed to be unity, and the ratio $\gamma_{A m} / \gamma_{P u}$ is approximately one. The values for the activity coefficients of the actinide chlorides are not expected to be unity, since large deviations from ideal behavior have been found for some molten salt solvents. However, the ratio of the activity coefficients for the two trichlorides is expected to be close to unity, even though the individual values may be on the order of $10^{-3}$. The two trivalent cations have nearly equal radii. Therefore, the mole-fraction equilibrium constant for the trivalent reaction is approximately equal to the activity equilibrium constant, or $K_{3 x} \approx K_{3 a}$. It is a function

\footnotetext{
${ }^{20}$ L. R. Morss, The Chemistry of the Actinide Elements, eds., J. J. Katz, G. T. Seaborg, and L. R. Morss, Second Edition, Vol. 2, p. 1304, Chapman \& Hall, London (1986).

${ }^{21}$ Irving Johnson, "The Thermodynamic Properties of Americium Dichloride and Americium Trichloride," unpublished information (January 1, 1989).

${ }^{22}$ F. H. Ellinger, K. A. Johnson, and V. O. Struebing, J. Nucl. Mater. 20, 83 (1966).
} 
of temperature but, to a good approximation, not dependent on either the composition of the liquid $\mathrm{Pu}$ or the composition of the molten salt.

The value for $K_{2 x}$ cannot be as simply treated, because its dependence on the molten salt composition leads to the dependence of the partition on the molten salt composition. Values of $\gamma_{A m}$ and $\gamma_{P u}$ can still be assumed to be close to unity, but the values of the activity coefficients of the two halides can no longer be assumed to be equal, since both the charge and ionic radii are different: $\mathrm{Am}^{+2}$ radius $=1.19 \AA$, and $\mathrm{Pu}^{3+}$ radius $=1.07 \AA$. Even if the two values were equal, they would not cancel out except when both are unity, which is highly unlikely. Therefore,

$$
K_{2 x}^{1 / 3} \cong K_{2 a}^{1 / 3} \times \frac{\gamma_{\mathrm{PuCl}_{3}}^{2 / 3}}{\gamma_{\mathrm{AmCl}_{2}}}
$$

The effect of the salt composition on the two activity coefficients in Eq. 3-18 largely accounts for the difference in Am extraction observed when the salt composition is changed. When these values are substituted in Eq. 3-17, the following relation is obtained:

$$
D_{A m} \approx\left\langle K_{3 a} \times D_{P u}\right\rangle+\left\langle K_{2 a}^{1 / 3} \times \frac{\gamma_{P u C l_{3}}^{2 / 3}}{\gamma_{A m C l_{2}}} D_{P u}^{2 / 3}\right\rangle
$$

Only the ratio of activity coefficients is a function of the salt composition. Unfortunately, there are very few published values for the activity coefficient of $\mathrm{AmCl}_{2}$ in different molten salt solvents, and this equation cannot be used to directly compute the Am distribution coefficient from the $\mathrm{Pu}$ distribution coefficient. However, it can be used to compute values for the activity coefficient of $\mathrm{AmCl}_{2}$ in various molten salt solvents from the observed distribution coefficients, and these values can be examined to determine whether their variation is consistent with what is known about the nature of the molten salt solvents.

Experimental measurements have been made ${ }^{23}$ at Los Alamos Scientific Laboratory (LASL) to determine the extent of extraction of Am from liquid $\mathrm{Pu}$ in which molten $\mathrm{LiCl}, \mathrm{NaCl}$, $\mathrm{KCl}, \mathrm{CsCl}$, or $\mathrm{CaCl}_{2}$ is used as the salt solvent. The oxidant was $\mathrm{PuCl}_{3}$. It was found that the extent of extraction was greatest for $\mathrm{CaCl}_{2}$, and then decreased as the alkali chloride was changed from $\mathrm{LiCl}$ to $\mathrm{CsCl}$. The smallest extraction was obtained with $\mathrm{CsCl}$ as the molten salt solvent. The Los Alamos workers also measured the extraction of Am from liquid Pu, using many other combinations of these molten salts. Since all these data were obtained during routine operations to purify metallic $\mathrm{Pu}$, only the starting amount of $\mathrm{Am}$ and the amount of $\mathrm{Am}$ remaining in the $\mathrm{Pu}$ after the extraction was completed were known. Hence, the various concentrations in the salt had to be estimated from the material balance. Since ${ }^{141} \mathrm{Am}$ grows in from the ${ }^{141} \mathrm{Pu}$, a correction had to be made for the time that elapsed between the extraction experiment and the analysis. There may have been some interaction with the extraction vessel, and some of the data had to be

${ }^{23}$ M. H. West, Los Alamos Scientific Laboratory, private communication (1989). 
rejected. Nevertheless, analysis of these data yields valuable insight into the effect of the salt composition on the partition.

To analyze the LASL data, the activity coefficient ratio in Eq. 3-19 was computed from the observed distribution data. From estimates of the activity coefficient of $\mathrm{PuCl}_{3}$ in the various molten salt solvents, the activity coefficient of $\mathrm{AmCl}_{2}$ was computed. The variation of these values with molten salt composition was examined to determine whether it was consistent with the variation found for other solutes. Some uncertainty is involved because the values for the activity coefficients of $\mathrm{PuCl}_{3}$ were not all based on experimental measurements. The activity coefficient ratios computed from the LASL data are shown plotted against the ionic potentials 24 for the molten salt in Fig. 3-1. A trend of increasing activity coefficient ratio with ionic potential is seen. To determine how the activity coefficient of $\mathrm{AmCl}_{2}$ varies with the salt composition, the activity coefficients of $\mathrm{PuCl}_{3}$ in each molten salt must be estimated. This was done using the data reported by Silin and Skiba ${ }^{25}$ for the four alkali chlorides, and their correlation was used to estimate the value for $\mathrm{CaCl}_{2}$.

The activity coefficients for $\mathrm{AmCl}_{2}$ are shown in Fig. 3-2. Except for the point for $\mathrm{LiCl}$ (ionic potential of 1.5), the values show a regular variation with the ionic potential. Considering the numerous assumptions made in these calculations, it seems reasonable to suggest that the activity coefficient of $\mathrm{AmCl}_{2}$ in these five molten salts ranges from about 0.2 to 0.7 as the ionic potential varies from 0.5 to 2 . The activity coefficient for $\mathrm{PuCl}_{3}$ over the same range of ionic potential is from 0.05 to 10 . Thus, the variation in the partition is mainly due to the approximately three orders of magnitude variation in the activity coefficient of $\mathrm{PuCl}_{3}$ as the composition of the molten salt is changed. In other words, the high values for the distribution ratios obtained for molten salts with high ionic potential are attributable to the large values for the activity coefficients of $\mathrm{PuCl}_{3}$ in these molten salts. This result would not have been obtained if divalent Am did not play an important role in the distribution.

The original partition data obtained by Mullins et al. ${ }^{17}$ have been analyzed by the method described above for the other LASL data. In this case, great care had been taken to measure the Am content of both the liquid $\mathrm{Pu}$ and the molten salt phase by taking samples of the liquids at the test temperature. Additions of $\mathrm{PuCl}_{3}$ (up to 8 to $10 \%$ ) were made to an equimolar molten mixture of $\mathrm{NaCl}$ and $\mathrm{KCl}$ at three temperatures: 698,730 , and $775^{\circ} \mathrm{C}$. Values of $\mathrm{K}_{2 \mathrm{x}}$ were computed from the observed distribution coefficients at each temperature. From the values for $\mathrm{K}_{2 \mathrm{a}}$ at each temperature, values for the activity coefficient ratio $\left(\gamma_{\mathrm{PuCl}_{3}}^{2 / 3} / \gamma_{\mathrm{AmCl}_{2}}\right)$ were computed. To compute $\gamma_{\mathrm{AmCl} 2}$, the activity coefficient for $\mathrm{PuCl}_{3}$ had to be estimated.

Since the mole fraction of $\mathrm{PuCl}_{3}$ was not insignificant, it was necessary to correct the activity coefficient for concentration. This was done by using the results of the analysis of the $\mathrm{PuCl}_{3}-\mathrm{KCl}-\mathrm{NaCl}$ system by Gohil et al. ${ }^{26}$ The results of these computations are shown in

\footnotetext{
${ }^{24}$ The ionic potential equals the charge divided by the ionic radius.

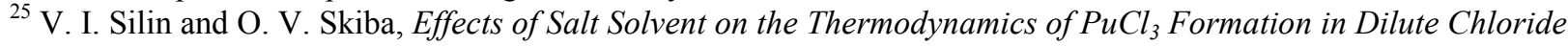
Solutions, English translation prepared at ANL of a Soviet research report (1971).

${ }^{26}$ D. D. Gohil, T. G. Ghart, and M. H. Rand, Calculated Phase Equilibria for the $\mathrm{KCl}-\mathrm{NaCl}-\mathrm{PuCl} 3 \mathrm{System}_{\text {, National }}$ Physical Laboratory Report DMA (D) 519 (March 1986).
} 
Fig. 3-3. It can be seen that, as the temperature is increased, the activity coefficients increase. This is expected since systems usually approach ideal behavior as the temperature is increased. In these experiments about 15 to $20 \%$ of the Am in the salt was in the trivalent form. Thus, it would be easy to miss this small amount and conclude that all of the Am is divalent. The fact that a major fraction of the Am is divalent in these experiments explains why the partition was dependent on the molten salt composition, since if only trivalent species were involved, no large effect from the salt composition would be expected.

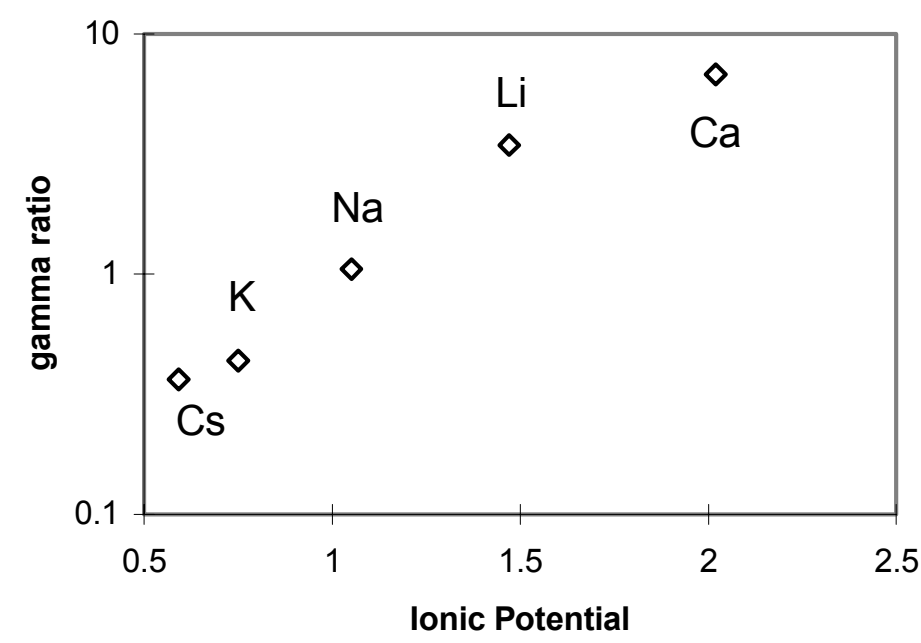

Fig. 3-1. Ratio of Activity Coefficient of $\mathrm{PuCl}_{3}$ (2/3 power) to $\mathrm{AmCl}_{2}$ Computed from LASL Data ${ }^{23}$ as Function of the Ionic Potential for the Molten Salts $\mathrm{CsCl}$ through $\mathrm{CaCl}_{2}$

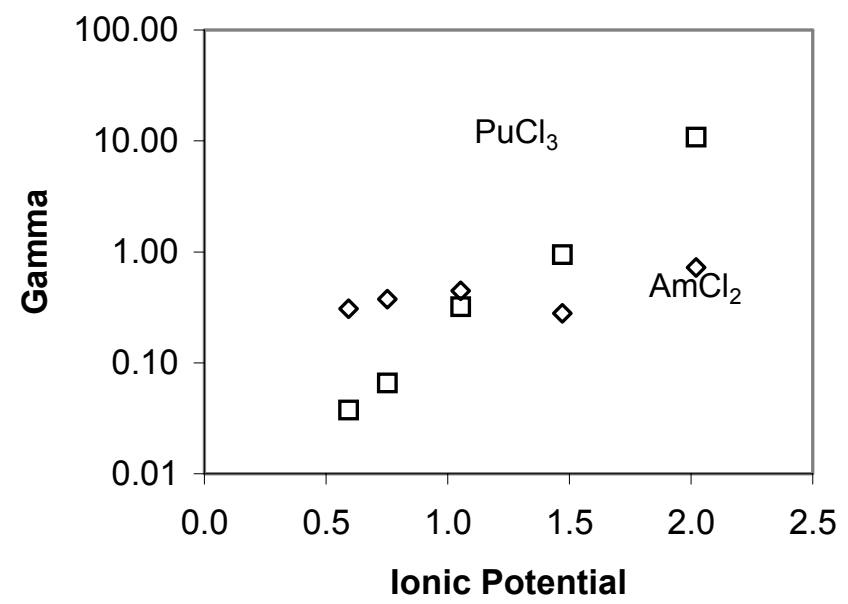

Fig. 3-2. Activity Coefficients of $\mathrm{AmCl}_{2}$ and $\mathrm{PuCl}_{3}$ in Various Molten Salts as Function of the Ionic Potential. The $\mathrm{PuCl}_{3}$ values are from Silin and Skiba. ${ }^{25} \mathrm{The} \mathrm{AmCl}_{2}$ values are computed from the LASL data for the partition of Am between liquid $\mathrm{Pu}$ and various molten salts. See Fig. 3-1 for identification of the salts used. 


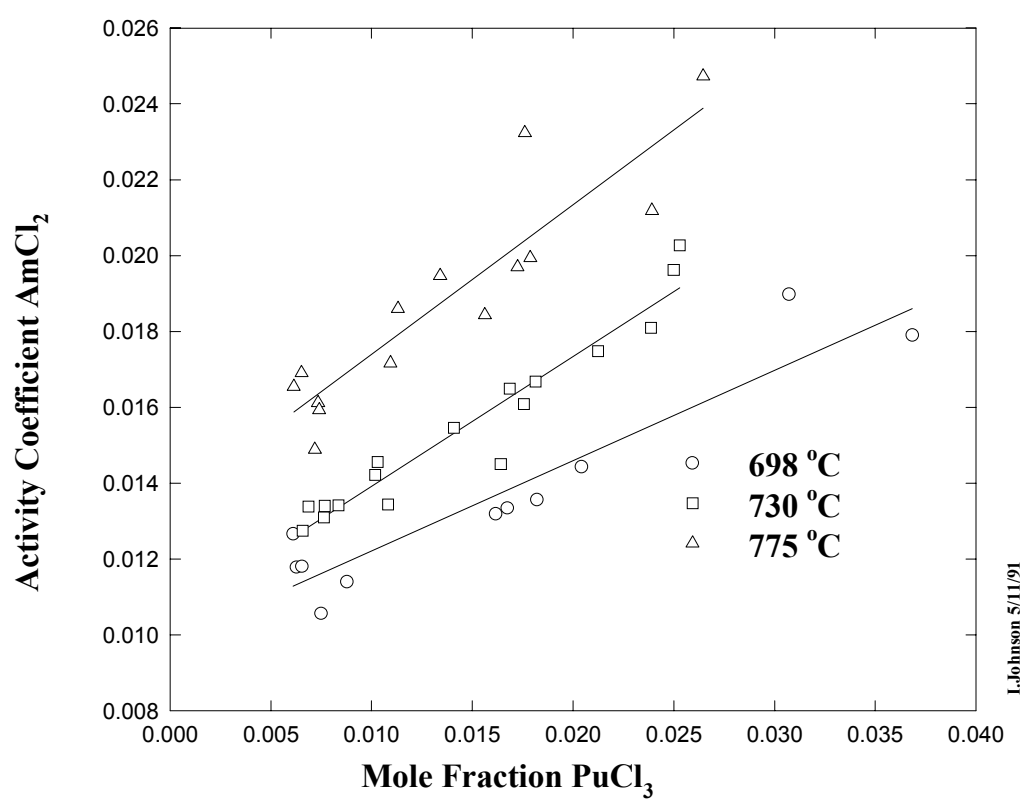

Fig. 3-3. Activity Coefficients of $\mathrm{AmCl}_{2}$ in Molten $\mathrm{KCl}-\mathrm{NaCl}$ Computed from Distribution of Am between Liquid $\mathrm{Pu}$ and the Molten Salt. Experimental data from Mullins et al. ${ }^{17}$

\section{E. Distribution between Liquid $\mathrm{Mg}-\mathrm{Zn}$ and $\mathrm{Molten} \mathrm{MgCl}_{2}$ Solutions}

The original thermodynamic analysis of experimental data for the partition between liquid metals and molten salts was done to understand the large variations in the distribution coefficients that Jim Knighton found when he varied the $\mathrm{Mg}$ concentration of liquid $\mathrm{Mg}-\mathrm{Zn}$ alloys. These analyses ${ }^{27}$ laid the foundation for all of the work that has been done since. In these experiments, Knighton made up a solution of the solute metal, U, Pu, Ce, La, etc., in a liquid Mg$\mathrm{Zn}$ alloy (or other $\mathrm{Mg}$ alloys), which he then contacted with a molten salt containing $\mathrm{MgCl}_{2}$. Filtered samples of the two immiscible liquids were taken and analyzed for the solute content. The liquid metal sample was usually also analyzed for its $\mathrm{Mg}$ content. Additions of $\mathrm{Mg}$ were then made to the liquid alloy, and after equilibrium had been established, samples were taken and analyzed. Usually, several starting alloys were used to facilitate the study of the $\mathrm{Mg}$ - and $\mathrm{Zn}$-rich regions. Knighton found that, in a typical experiment, the distribution coefficient first decreased,

${ }^{27}$ Irving Johnson, "Partition of Metals between Liquid Metal Solutions and Fused Salts," in Applications of Fundamental Thermodynamics to Metallurgical Processes, ed., G. R. Fitterer, Gordon and Beach, New York, pp. 153-177 (1967). Presented at a conference held at the University of Pittsburgh, November 29-December 1, 1964. 
passed through a minimum value, and then increased as the $\mathrm{Mg}$ concentration was increased. The explanation of this behavior was one of the early cases where the value of analyses based on thermodynamics was established. To describe the analysis, the distribution of uranium between liquid $\mathrm{Mg}-\mathrm{Zn}$ and molten $\mathrm{MgCl}_{2}$ will be considered.

The distribution reaction may be written as follows:

$$
U_{C l}\left(\text { molten } M g C l_{2}\right)+\frac{3}{2} M g(l i q M g-Z n)=U(\text { liq } M g-Z n)+\frac{3}{2} M_{g C l}(\text { salt })
$$

Hence, the equilibrium relation may be written:

$$
\frac{a_{U} a_{M g C l_{2}}^{3 / 2}}{a_{U C l_{3}} a_{M g}^{3 / 2}}=K_{a}
$$

The distribution coefficient for $\mathrm{U}$ is given by

$$
D_{U}=\frac{1}{K_{a}} \times\left(\frac{a_{M_{g C l_{2}}}}{a_{M g}}\right)^{3 / 2} \times \frac{\gamma_{U}}{\gamma_{U C l_{3}}}
$$

In the original analysis, the three factors in Eq. 3-22 were rearranged, after logarithms were taken of both sides of the equation, and called the "reaction potential," the "reduction potential," and the "oxidation potential," respectively. The following are the definitions of the three potentials:

$$
\begin{aligned}
& p K_{a}=-\log K_{a} \\
& p R=-\frac{3}{2} \log a_{M g}+\log \gamma_{U} \\
& p O=-\frac{3}{2} \log a_{M g C l_{2}}+\log \gamma_{U C l_{3}}
\end{aligned}
$$

These three "potentials" are independent of each other. The reaction potential depends only on the thermodynamics of the redox system, the reduction potential depends only on the liquid metal system, and the oxidation potential depends only on the molten salt system. (The influence of aqueous thermodynamics is seen in these three potentials.) This development allowed the liquid metal and the molten salt solution thermodynamics to be treated separately. With these definitions, the distribution coefficient can be written as:

$$
\log D_{U}=p K_{a}+p R-p O
$$

For the distribution of $\mathrm{U}$ between liquid $\mathrm{Mg}-\mathrm{Zn}$ solutions and molten $\mathrm{MgCl}_{2}, p K_{a}$ and $p O$ are constant (assuming Henry's law for the dilute $\mathrm{UCl}_{3}-\mathrm{MgCl}_{2}$ solution). Only the variation in $p R$ with the composition of the liquid $\mathrm{Mg}-\mathrm{Zn}$ solution needs to be considered.

The reduction potential can be expanded as: 


$$
p R=-\frac{3}{2} \log x_{M g}-\frac{3}{2} \log \gamma_{M g}+\log \gamma_{U}
$$

All three terms are a function of the $\mathrm{Mg}$ (and possibly the $\mathrm{U}$ ) content of the liquid metal solution. Since the concentration of $U$ in these liquid metal solutions was small, it was assumed that the activity coefficients of $\mathrm{Mg}$ in the Mg-Zn solutions could be used. The activity coefficient of $\mathrm{U}$ in the binary $\mathrm{Mg}-\mathrm{Zn}$ solution can be estimated from the D.A.R. relation ${ }^{28}$.

$$
\log \gamma_{U(m i x)}=x_{M g} \log \gamma_{U(M g)}+x_{Z n} \log \gamma_{U(Z n)}-\frac{\Delta G_{Z n-M g}^{x s}}{2.3 R T}
$$

where the $x$ 's are the mole fractions of $\mathrm{Mg}$ and $\mathrm{Zn}$ in the liquid metal solution; the $\gamma$ s, the activity coefficients of $\mathrm{U}$ dissolved in pure liquid $\mathrm{Mg}$ and $\mathrm{Zn}$ (at zero concentration); and $\Delta G^{x s}$, the excess Gibbs energy of mixing of the Mg-Zn solution of composition $x_{M g}$ and $x_{Z n}$.

The calculated and observed distribution coefficients are compared in Fig. 3-4. The two curves differ by the logarithm of the activity coefficient of $\mathrm{UCl}_{3}$ in molten $\mathrm{MgCl}_{2}, 0.252$, which corresponds to an activity coefficient of 1.8 .

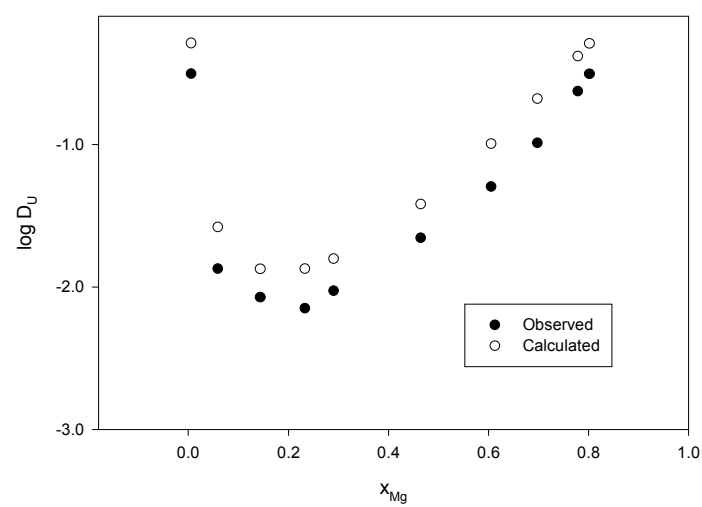

Fig. 3-4. Distribution Coefficients of Uranium between Molten $\mathrm{MgCl}_{2}$ and Liquid $\mathrm{Mg}-\mathrm{Zn}$ Solutions. Comparison of observed and calculated results.

In Fig. 3-4, if the calculated curve were displaced by 0.252 , it would fall almost exactly on the experimental data points. Numerical computations indicate that the average deviation between the computed and experimental values, when the 0.252 adjustment is applied, is less than 0.01 , or $2 \%$ of the distribution coefficient value. The value of 1.8 for the activity coefficient of $\mathrm{UCl}_{3}$ in the molten $\mathrm{MgCl}_{2}$ needed to bring the computed and experimental values of the distribution coefficients in agreement seems reasonable for the $\mathrm{UCl}_{3}-\mathrm{MgCl}_{2}$ system. Since this

\footnotetext{
${ }^{28}$ The Darkin-Alcock-Richardson relation is based on the studies of L. S. Darken (J. Amer. Chem. Soc. 72, 2909, 1950) and C. B. Alcock and F. D. Richardson (Acta. Metall. 8, 882, 1960).
} 
value contains all of the uncertainties of the other thermodynamic data, however, it should not be considered more than a rough estimate. An analysis of the $\mathrm{UCl}_{3}-\mathrm{MgCl}_{2}$ phase diagram 29 yields an activity coefficient for $\mathrm{UCl}_{3}$ of about 2.4 at $800^{\circ} \mathrm{C}$ and zero $\mathrm{UCl}_{3}$ concentration. Because the data obtained from phase diagrams determined by thermal analysis are not very accurate, the agreement is satisfactory.

\section{F. Activity Coefficients in Liquid Metal Solutions}

The successful analysis of the kind of experimental partition data obtained by Knighton led to the development of a method for the determination of the activity coefficients of a metal in one liquid metal solvent from the value in another liquid metal solvent. This "boot strap" method has allowed values to be obtained for liquid metal solvents that would be difficult to measure directly. The method is based on Eq. 3-22. Assume that we have measured the activity coefficient of a metal, such as $\mathrm{Np}$, in a liquid metal solvent $A$, such as $\mathrm{Cd}$. We then carry out distribution coefficient measurements for $\mathrm{Np}$ between a molten salt containing $\mathrm{MgCl}_{2}$ (whose composition is constant, except for $\mathrm{NpCl}_{3}$ ) and liquid $\mathrm{Mg}$-Cd metal solutions. ${ }^{30}$ Rearranging Eq. 3-22 yields the following:

$$
\ln \gamma_{N p}=\ln D_{N p}+\frac{3}{2} \ln x_{M g}+\frac{3}{2} \ln \gamma_{M g}+\ln K_{s}
$$

where $K_{s}=K_{a} \gamma_{\mathrm{NPCl}_{3}} / a_{\mathrm{MgCl}_{2}}^{3 / 2}$, which will be constant for the small variation in the molten salt composition. From Eq. 3-27, we can derive the following relation:

$$
\begin{aligned}
& \ln \gamma_{N p(M g)}=\left(\ln D+\frac{3}{2} \ln x_{M g}\right)_{x_{M g} \rightarrow 1}-\left(\ln D+\frac{3}{2} \ln x_{M g}\right)_{x_{M g} \rightarrow 0} \\
& -\left(\frac{3}{2} \ln \gamma_{M g(C d)}\right)_{x_{M g} \rightarrow 0}+\ln \gamma_{N p(C d)}
\end{aligned}
$$

The limiting values of $\ln D+3 / 2 \ln x_{M g}$ can be obtained graphically from the experimental data (Fig. 3-5). Note that both $\ln D$ and $\ln x_{M g}$ are indeterminate at $x_{M g}=0$, but their difference can be obtained by graphical extrapolation. In addition to the experimental limiting values, the activity coefficient of $\mathrm{Mg}$ in an infinitely dilute solution and the activity coefficient of $\mathrm{Np}$ in $\mathrm{Cd}$ must be known to compute the activity coefficient of $\mathrm{Np}$ in liquid $\mathrm{Mg}$. The details of the computation are given in Table 3-1. The activity coefficient of $\mathrm{Pu}$ in liquid $\mathrm{Mg}$ has also been determined using this method. ${ }^{32}$ In addition, much of the distribution data summarized by Knighton ${ }^{12}$ have been analyzed, and where possible, activity coefficient data have been extracted. These results have not been published.

\footnotetext{
${ }^{29}$ V. N. Desyatnik, B. V. Dubinin, Yu. T. Mel'nikov, and S. P. Raspopin, Russian J. Inor. Chem. 20, 608-609 (1976), Engl. Trans. Note the temperature on the figure should be $600^{\circ} \mathrm{C}$, not $500^{\circ} \mathrm{C}$.

${ }^{30}$ The example that we use has been published: I. Johnson, J. J. Heiberger, and J. Fischer, Met. Trans. 1, 1253 (1970).

${ }^{31}$ As the concentration of $\mathrm{Mg}$ approaches zero, some other redox couple would take control, so it is necessary that the measurements not be made too close to zero $\mathrm{Mg}$ concentration.

${ }^{32}$ I. Johnson, J. B. Knighton, and R. K. Steunenberg, Trans. Met. Soc. AIME 236, 1242 (1966).
} 


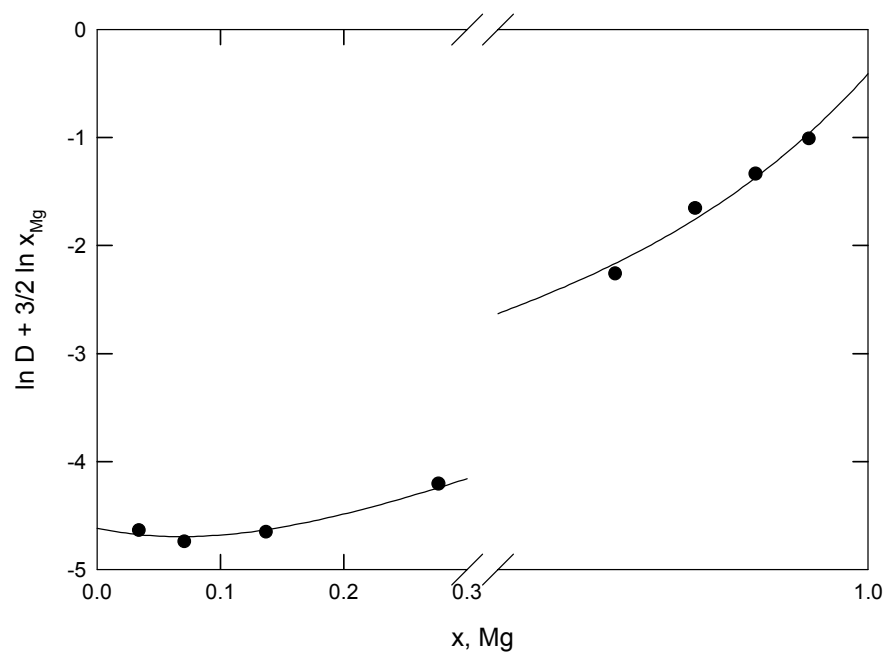

Fig 3-5. Limiting Values of $\ln \mathrm{D}+3 / 2 \ln \mathrm{x}_{\mathrm{Mg}}$ for Distribution of $\mathrm{Np}$ between Molten $\mathrm{MgCl}_{2}-\mathrm{NaCl}-\mathrm{KCl}$ and Liquid $\mathrm{Mg}-\mathrm{Cd}$ Solution at $650^{\circ} \mathrm{C}$

Table 3-1. Activity Coefficients of Neptunium Dissolved in Liquid Magnesium Computed from Distribution Data. See Eq. 3-28.

\begin{tabular}{|l|c|c|}
\hline & $\mathbf{6 5 0}^{\mathbf{}} \mathbf{C}$ & $\mathbf{7 0 0}^{\mathbf{0}} \mathbf{C}$ \\
\hline$\left[\ln \mathrm{D}+3 / 2 \ln \mathrm{x}_{\mathrm{Mg}}\right]_{\mathrm{Mg} \rightarrow 0}$ & -4.525 & -4.170 \\
\hline$\left[\ln \mathrm{D}+3 / 2 \ln \mathrm{x}_{\mathrm{Mg}}\right]_{\mathrm{Mg} \rightarrow 1}$ & -0.700 & -0.525 \\
\hline $3 / 2 \ln \gamma_{\mathrm{Mg}(\mathrm{Cd})}^{\mathrm{o}}$ & -3.271 & -3.064 \\
\hline $\ln \gamma_{\mathrm{Np}(\mathrm{Cd})}$ & -3.946 & -3.934 \\
\hline $\ln \gamma_{\mathrm{Np}(\mathrm{Mg})}, \gamma_{\mathrm{Np}(\mathrm{Mg})}$ & $3.150,23.3 \pm 5.0$ & $2.775,16.0 \pm 5.0$ \\
\hline
\end{tabular}

\section{G. Summary}

These analyses of distribution data have demonstrated that, in addition to the expected dependence on the Gibbs energy change of the reaction (and, hence, the thermodynamic equilibrium constant) the activity coefficients of the solutes in both the molten salt and liquid metal solutions can have a large effect. In many cases, this effect can be so large that the Gibbs energy change is completely overshadowed. As a practical matter, the liquid metal solution often has a tendency to bring the distribution coefficients of different solutes closer together and, therefore, to negate large differences in equilibrium constants. This effect is highly dependent on 
the specific liquid metal system. For example, the separation of $\mathrm{Pu}$ and $\mathrm{U}$ is good with most liquid $\mathrm{Mg}-\mathrm{M}$ systems. However, the separation of the lanthanides from $\mathrm{Pu}$ is poor for most lowmelting Mg-M systems. Knighton's discovery of the good separations achievable with liquid Mg$\mathrm{Cu}$ solutions made development of a high-decontamination pyrochemical process possible.

The molten salt-liquid metal distribution is important to the operation of electrotransport and salt transport processes. All redox-based pyrochemical processes depend on differences in distribution coefficients between two phases, one of which is metallic and one non-metallic, i.e., usually a molten salt. The analyses illustrated in this section enable accurate predictions to be made. 


\section{THERMODYNAMICS OF LIQUID METAL SOLUTIONS}

A major activity during the early years of the CEN/CMT pyrochemical program was the development of a method for treating the thermodynamics of liquid metal solutions. In this section, we review the development of this treatment beginning in 1957 since it differs in some ways from the conventional treatments found in thermodynamic texts. 33 Our first interest was understanding the solubility of various metals, especially $\mathrm{U}$ and $\mathrm{Pu}$, in low melting metals such as $\mathrm{Zn}, \mathrm{Cd}, \mathrm{Mg}$, and their mixtures. This interest arose, in part, because the Division was involved in the development of processes for the Experimental Breeder Reactor-II, which employed a metallic fuel. In particular, the Division had developed a "melt refining" process to keep the uranium in the metallic form. The early studies focused on solubilities. Later, when separations based on partition between liquid alloys and molten salts became the major interest, the methods developed for understanding the solubilities were found to be useful for treating the thermodynamics of the liquid metal alloy, as discussed in Sec. III.

\section{A. Definition of Solubility}

The solubility of a solute metal in a liquid metal solvent is defined as the solute metal content of the liquid metal solution (expressed as either weight percent, atomic percent, or atom fraction) when in equilibrium with a solid (or another liquid) solute metal-rich phase. This definition of solubility, which differs from that commonly used by chemists, was adopted as a practical expedient during the early pyrochemical studies when it was not feasible or necessary to completely characterize the equilibrium solid phase. Chemist commonly refer to the solubility of a particular solid rather than a main constituent of the solid. But we were dealing with a singleelement solute metal dissolved in a liquid metal solvent. We thus believed that it was incorrect to state solubilities in liquid metal solutions in terms of the formula for the equilibrium solid phase, since the formula of any molecular entities (species) which may exist (if any do) in the liquid metal solution would not be expected to be related in any simple way to the formula of the solid phase. This also applies to the solubilities of many salts in water. It was only after Arrhenius ( $c a$. 1887) demonstrated that "molecules" of $\mathrm{NaCl}$ did not exist in aqueous solutions that the solubilities of salts were understood. Later it was found, with the development of X-ray diffraction, that "molecules" of $\mathrm{NaCl}$ did not exist in the solid. However, molecules of $\mathrm{NaCl}$ do exist in the vapor over solid or liquid at high temperatures.

Note that we do not assume that information concerning the composition and structure of the equilibrium solid phase is superfluous for the complete specification of the solubility equilibria, only that this information is not needed to derive numerical values for the solubility, which are extremely useful for development of practical processes. Indeed, the thermodynamic analysis of solubility equilibria, which will be presented in this section, requires knowledge of the composition and the thermodynamic properties of the solid phase in equilibrium with the liquid solution. Even when knowing the composition and structure of the solid metallic phase, we will refer to the solubility in terms of the amount of the main element in the liquid solution. In

\footnotetext{
${ }^{33}$ An excellent modern text is C. H. P. Lupis, Chemical Thermodynamics of Materials, Elsevier Science Publishing Co., New York (1983).
} 
the remainder of this section, we will illustrate solubility equilibria in binary and ternary systems using uranium and plutonium as solute metals.

\section{B. Binary Systems}

The solubility equilibria may be expressed by the following equation:

$$
M X_{m}(s)=M(s o l)+m X(s o l)
$$

where $\mathrm{MX}_{\mathrm{m}}$ is the formula for the solid phase in equilibrium with binary liquid solution of $\mathrm{M}$ (U or $\mathrm{Pu})$ and $\mathrm{X}(\mathrm{Zn}, \mathrm{Cd}, \mathrm{Mg}$, etc. $)$. The value of m may equal zero, in which case pure $\mathrm{M}$ is in equilibrium with the solution. The value of $m$ may have a constant value, in which case we refer to $\mathrm{MX}_{\mathrm{m}}$ as an intermetallic compound of $\mathrm{M}$ and $\mathrm{X}$. This is the "line" compound of the metallurgist. The value of $\mathrm{m}$ may also have a range of values, in which case the equilibrium solid phase is a solid solution. Probably, most line compounds have a small range of compositions since charge balance, as in ionic compounds, is not a factor in the determination of the composition of intermetallic compounds. We will usually neglect this small composition variation. The atom fraction of $\mathrm{M}$ in the saturated liquid solution, $\mathrm{x}_{\mathrm{M}}^{\mathrm{s}}$, is given by the equations:

$$
\begin{aligned}
& R T \ln a_{M}^{s}+m \ln a_{X}^{s}-\Delta_{f} G^{o}\left(M X_{m}\right)=0 \\
& \ln x_{M}^{s}=\frac{\Delta_{f} G^{o}\left(M X_{m}\right)}{R T}-\ln \gamma_{M}^{s}-m \ln a_{X}^{s}
\end{aligned}
$$

where $\Delta_{f} G^{o}\left(M X_{m}\right)$ is the standard Gibbs energy of formation of the compound per gram-atom of $\mathrm{M} ; \gamma_{M}$, the activity coefficient of $\mathrm{M}$; and $a_{X}$, the activity of $\mathrm{X}$ in the saturated solution. The same reference states must be used for all quantities.

1. Equilibrium Phase: Pure Solid Metal

In this example $\mathrm{m}=0$. If solid $\mathrm{M}$ is the reference state,

$$
\begin{aligned}
& \ln x_{M}^{s}=-\ln \gamma_{M}^{s} \\
& x_{M}^{s}=1 / \gamma_{M}^{s}
\end{aligned}
$$

If pure super-cooled liquid $\mathrm{M}$ is taken as the reference state, then Eq. 4-3 becomes

$$
\ln x_{M}^{s}=\frac{-\left(\Delta G_{f u s i o n}+\Delta \bar{G}_{M}^{x s(s)}\right)}{R T}
$$

\footnotetext{
${ }^{34}$ See Eqs. 2-12 and 2-13 for development of this relation.
} 
If the Gibbs energies are written in terms of the corresponding enthalpies and entropies, then Eq. 4-4 becomes

$$
\ln x_{M}^{s}=\frac{-\left(\Delta H_{\text {fusion }}+\bar{H}_{M}^{x s(s)}\right)}{R T}+\frac{\Delta S_{\text {fusion }}+\bar{S}_{M}^{x s(s)}}{R}
$$

In most cases in which the solid equilibrium phase is pure $\mathrm{M}$, the quantity $\Delta H_{\text {fusion }}+\Delta \bar{H}_{M}^{x s(s)}$ is positive, and the solubility increases with increasing temperature. However, in the U-Cd system ${ }^{25}$ $\bar{H}_{M}^{x s(s)}$ is negative and has a larger absolute value than $\Delta H_{f u s i o n}$, leading to a retrograde solubility of $\mathrm{U}$ in liquid $\mathrm{Cd}{ }^{36}$ over part of the temperature range. At lower temperatures, where the intermetallic compound $\mathrm{UCd}_{11}$ is the equilibrium solid phase, the solubility again increases with temperature. The retrograde solubility of uranium in cadmium is the only such example that has been reported for a liquid metallic solution.

Since the enthalpy and entropy terms are often not strongly dependent on temperature, a plot of the logarithm of the solubility $v s$. the reciprocal of the absolute temperature can be fit to a straight line. Caution should be exercised in using the slope and intercept to estimate enthalpies and entropies, however, since this method is notoriously unreliable.

\section{Equilibrium Phase: Intermetallic Compound}

When the solubility is small, $a_{X}$ is nearly unity, and Eq. 4-2 may be written in the

form:

$$
\ln x_{M}^{s}=\frac{\Delta_{f} H^{o}\left(M X_{m}\right)-\bar{H}_{M}^{*(s)}}{R T}-\frac{\Delta_{f} S^{o}\left(M X_{m}\right)-\bar{S}_{M}^{*(s)}}{R}
$$

where $\Delta_{f} H^{o}$ and $\Delta_{f} S^{\circ}$ are the standard enthalpy and entropy of formation of $\mathrm{MX}_{\mathrm{m}}$ at temperature T. In general, the reference states are liquid X and solid M. The quantities $H^{*}{ }_{M}$ and $S_{M}{ }_{M}$ are equal to the enthalpy and entropy terms in Eq. 4-5. The reference state for $\mathrm{U}$ and Pu used in our work is the solid. For all cases studied so far, $H^{*}{ }_{M}$ is smaller in absolute value than the enthalpy of formation of the intermetallic compound, and therefore, the solubility increases with an increase in temperature.

When the thermodynamic properties of the intermetallic compound and the liquid metallic solution are known, the solubility can be computed from either Eq. 4-2 or 4-6. As an example, Table 4-1 gives the calculated and observed results for the solubility of $\mathrm{Pu}$ in liquid $\mathrm{Cd}$ as a fupction of temperature. In this $\mathrm{Pu}-\mathrm{Cd}$ system, the results of high-temperature galvanic cell studies 37 indicated that the partial Gibbs energy function may be represented by the equation ${ }^{68}$.

\footnotetext{
${ }^{35}$ I. Johnson and H. M. Feder, Trans. Met. Soc. AIME 224, 468 (1962).

${ }^{36}$ A. E. Martin, I. Johnson, and H. M. Feder, Trans. Met. Soc. AIME 221, 789 (1961).

${ }^{37}$ I. Johnson, M. G. Chasanov, and R. M. Yonco, Trans. Met. Soc. AIME 233, 1408 (1965).
} 


$$
\bar{G}_{P u}^{x s}=R T \ln \gamma_{P u}=\left(1-x_{P u}\right)^{2}\left(A+B x_{P u}\right)
$$

where $\mathrm{A}$ and $\mathrm{B}$ are linear functions of the temperature. The free energies of formation of the intermetallic compounds $\mathrm{PuCd}_{11}$ and $\mathrm{PuCd}_{6}$ were found to be a linear function of the temperature. The excess free energy of Cd was computed from Eq. 4-7 and the Gibbs-Duhem relation. These equations were substituted into Eq. 4-2, and the resulting transcendental equation was solved for $\mathrm{x}_{\mathrm{Pu}}$ at each temperature. Table 4-1 gives the calculated $\mathrm{x}_{\mathrm{Pu}}$ 's. The agreement between computed and observed solubilities is satisfactory.

Figure 4-1 shows the temperature dependence of the solubilities of $\mathrm{U}, \mathrm{Np}$, and $\mathrm{Pu}$ in liquid $\mathrm{Cd}$. At lower temperatures all three actinides form the cubic intermetallic compound $\mathrm{AnCd}_{11}$, and the slopes of the solubility lines are almost parallel. The slopes are proportional to the difference between the enthalpy of formation and the partial excess enthalpy of the actinide in the liquid $\mathrm{Cd}$ solution (Eq. 4-6). While both terms vary from $\mathrm{U}$ to $\mathrm{Pu}$, their difference is approximately constant. The $\mathrm{AnCd}_{11}$ compounds peritectically decompose into a solid phase that contains less $\mathrm{Cd}$. In the case of $\mathrm{Np}$ and $\mathrm{Pu}$, the next phase is the $\mathrm{AnCd}_{6}$ intermetallic compound. The intersection of the two solubility lines permits the peritectic point to be accurately determined. In the case of uranium, the next phase is pure uranium, which as mentioned above, has a retrograde solubility, i.e., its solubility decreases with increasing temperature. These solubility lines suggest that the experimental data can only be extrapolated to higher temperatures when it is certain that the equilibrium solid phase remains the same. For example, if the lowtemperature $\mathrm{PuCd}_{11}$ line were extrapolated to $500^{\circ} \mathrm{C}$, the computed solubility would be too large.

Table 4-1. Comparison of Observed and Calculated Solubilities of Plutonium in Liquid Cadmium. Atom fraction solubilities.

\begin{tabular}{|c|c|c|c|}
\hline Temp., ${ }^{\circ} \mathrm{C}$ & $\mathrm{X}_{\mathrm{Pu}}$ (obs) & $\mathrm{X}_{\mathrm{Pu}}$ (calc) & Solid Phase \\
\hline 335 & 0.00156 & 0.00152 & $\mathrm{PuCd}_{11}$ \\
\hline 351 & 0.00222 & 0.00223 & $\mathrm{PuCd}_{11}$ \\
\hline 388 & 0.00549 & 0.00500 & $\mathrm{PuCd}_{11}$ \\
\hline 408 & 0.00773 & 0.00680 & $\mathrm{PuCd}_{6}$ \\
\hline 443 & 0.0109 & 0.0101 & $\mathrm{PuCd}_{6}$ \\
\hline 504 & 0.0187 & 0.0181 & $\mathrm{PuCd}_{6}$ \\
\hline 544 & 0.0284 & 0.0275 & $\mathrm{PuCd}_{6}$ \\
\hline 603 & 0.0414 & 0.0402 & $\mathrm{PuCd}_{6}$ \\
\hline 632 & 0.0544 & 0.0501 & $\mathrm{PuCd}_{6}$ \\
\hline
\end{tabular}

\footnotetext{
${ }^{38}$ This is the "sub-regular" solution model.
} 


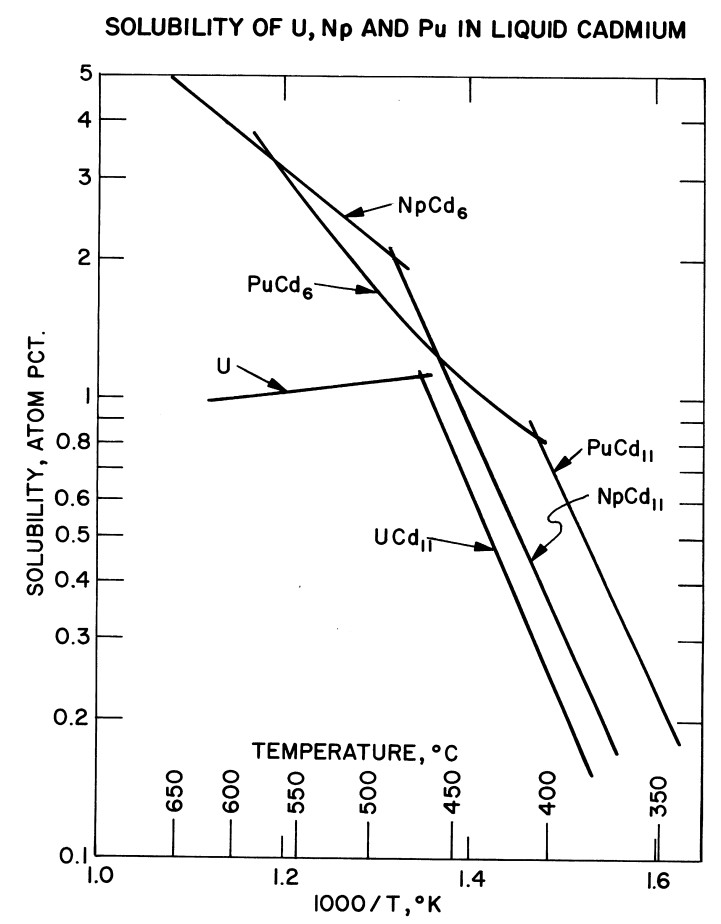

Fig. 4-1. Solubility of $\mathrm{U}, \mathrm{Pu}$, and $\mathrm{Np}$ in Liquid $\mathrm{Cd} v s$. Temperature

\section{Ternary Systems}

Ternary systems of $\mathrm{U}$ and $\mathrm{Pu}$ with mixtures of two low melting metals, such as Cd-Mg or $\mathrm{Zn}-\mathrm{Mg}$, will be considered here. Only the solvent-rich region of the ternary system will be discussed, although the methods may, in principle, be extended to the whole ternary system. The solubility of $\mathrm{U}$ or Pu may be represented by the following general equilibria:

$$
M X_{m} Y_{n}(s)=M(s o l)+m X(s o l)+n Y(s o l)
$$

where $\mathrm{MX}_{\mathrm{m}} \mathrm{Y}_{\mathrm{n}}$ is the formula for the solid phase in equilibrium with the liquid metallic solution of $\mathrm{U}$ or $\mathrm{Pu}$ and $\mathrm{X}$ and $\mathrm{Y}(\mathrm{Cd}, \mathrm{Zn}, \mathrm{Mg}$, etc.). The parameters $\mathrm{m}$ and $\mathrm{n}$ can be zero, one could be constant, or both could be constants. The formula for the solid phase may not be the same over the whole composition range of the binary solvent system. This realization led to our first application of thermodynamics to solubilities in ternary systems.

The solubility of $\mathrm{M}$ in the liquid phase is given by the equation:

$$
\ln x_{M}^{s}=\frac{\Delta_{f} G^{o}\left(M X_{m} Y_{n}\right)}{R T}-\ln \gamma_{M}^{s}-m \ln a_{X}^{s}-n \ln a_{Y}^{s}
$$


in which $\Delta_{f} G^{o}\left(M X_{m} Y_{n}\right)$ is the standard Gibbs energy of formation of $M X_{m} Y_{n}$ (per gram-atom of $\mathrm{M})$. In general, because the extensive thermodynamic data needed are not available, the a priori calculation of solubility values using Eq. 4-9 is not practical without use of some simplifying assumptions. Fortunately, in the cases of the solubility of $\mathrm{U}, \mathrm{Pu}$, and many fission product elements in low-melting solvent metals, several methods have been developed for estimating the required thermodynamic data.

The principal method developed for estimating solubilities in binary liquid metallic solvents requires data for (1) the solubility of $\mathrm{M}$ in the two solvent metals, (2) the Gibbs energy of formation of any intermetallic compounds, and (3) the activities of X and $\mathrm{Y}$ in the binary $\mathrm{X}-\mathrm{Y}$ liquid solvent. In addition, the probability of the formation of a ternary intermetallic compound must be evaluated. This method, to be described here, has proven useful for the rapid estimation of solubilities in solvents proposed for new processes, the guidance of experimental solubility studies, and the interpolation and extrapolation of experimental thermodynamic data.

Usually, a decision regarding the possible existence of a ternary intermetallic compound can be made by considering the compositions and crystal structures of any compounds found in the binary M-X and M-Y systems. (Obviously, the X-Y system must be miscible and liquid over the composition range where it is to be used as a liquid solvent.) If intermetallic phases do not exist in either binary system, or only exist in one of the binary systems, then the existence of a ternary compound is very unlikely. When intermetallic compounds exist in both binary systems, then the existence of a ternary intermetallic compound is more probable. A comparison of the crystal structures of the binary compounds, together with consideration of the radii of the elements involved, will aid in evaluating the possible existence of a ternary compound. If both intermetallic compounds have the same structure, the probability of a ternary compound or a solid solution is high.

While we have formulated the ternary system as composed of one solute metal and two solvent metals, also possible are ternary systems composed of two solute metals and one solvent metal. In this latter case we have found conditions where the existence of ternary intermetallic phases may affect solubility. Separations of $\mathrm{U}$ and $\mathrm{Pu}$ from each other and from the lanthanide metals using solubility differences are severely limited when intermetallic compounds in which the solvent metal has the same crystal structure are formed. Moriarty et al. . $^{6}$ considered this situation in terms of co-precipitation. In the early 1990s, Ackerman and Settle ${ }^{40}$ studied the cosolubility of various lanthanides in liquid cadmium. They discussed their experimental results in terms of the formation of a solid solution of the lanthanides in the intermetallic compounds, which have the formula $\mathrm{LnCd}_{11}$ or $\mathrm{LnCd}_{6}$.

The first term on the right-hand side of Eq. 4-9 may be determined from the Gibbs energies of formation that have been reported for several $\mathrm{U}$ and $\mathrm{Pu}$ intermetallic compounds. The next term (the activity coefficient, $\gamma_{M}$, in the binary solvent) may be estimated using the geometric mean approximation:

\footnotetext{
${ }^{39}$ J. L. Moriarty, I. Johnson, and H. M. Feder, Trans. Met. Soc. AIME 230, 777 (1964).

${ }^{40}$ J. P. Ackerman and J. Settle, J. Alloys Comp. 199, 77 (1993); ibid., 177, 124 (1991).
} 


$$
\ln \gamma_{M}=x_{X} \ln \gamma_{M, X}+x_{Y} \ln \gamma_{M, Y}+\text { correctionterm }
$$

where $x_{X}$ and $x_{Y}$ are the atom fractions of the solvent metals, and $\gamma_{M, X}$, and $\gamma_{M, Y}$ are the activity coefficients of $\mathrm{M}$ in the two pure solvents. The "correction term" may be assumed to be zero for a first approximation. A better estimate is obtained by using the D.A.R. ${ }^{4}$ expression for the correction term:

$$
\text { (correction term, D.A.R.) }=\frac{-\Delta_{m i x} G_{X-Y}^{x s}}{R T}
$$

where $\Delta_{m i x} G^{x s}{ }_{X-Y}$ is the excess Gibbs energy of mixing of the X-Y solvent system at the composition given by $\mathrm{x}_{\mathrm{X}}$ and $\mathrm{x}_{\mathrm{Y}}$. The activities of the solvent metal can be computed from the activities in the binary system (if known).

The activity coefficients of $\mathrm{M}$ in the two pure solvent metals may be computed from the solubility of $\mathrm{M}$ in the solvent metal and the Gibbs energy of formation of the intermetallic compound:

$$
\ln \gamma_{M}=\frac{\Delta_{f} G_{M X_{m}}^{o}}{R T}-\ln x_{M}^{s a t^{\prime} d}-m \ln a_{X}
$$

Since the solubilities are usually small, the activity of the solvent metal, ax, may be set equal to the mole fraction. As indicated above, when the pure solute is the equilibrium solid phase, the activity coefficient is equal to the reciprocal of the solubility. Consult the publications on the $\mathrm{U}-\mathrm{Cd}^{35}$ and $\mathrm{Pu}-\mathrm{Cd}^{37}$ systems for more detailed accounts.

The method developed will be illustrated by a consideration of the solubility of $U$ in the liquid Mg-Zn solvent system. Figure 4-2 gives experimental values of the solubility of uranium in liquid $\mathrm{Zn}-\mathrm{Mg}$ solutions at $800^{\circ} \mathrm{C}$ as a function of the atom fraction of $\mathrm{Mg}$. The experimental data are from the work of Martin and Wach ${ }^{43}$ and Knighton et al. ${ }^{44}$ The unusual behavior of the variation of the solubility with the $\mathrm{Mg}$ content of the liquid $\mathrm{Zn}-\mathrm{Mg}$ solution was very puzzling until it was realized that the equilibrium solid phase was different for the $\mathrm{Zn}$ - and the Mg-rich solutions. When Martin and Wach obtained their first results, thermodynamic data had just been obtained for $\mathrm{UZn}_{8.5}$, the solid phase believed to be in equilibrium with liquid $\mathrm{U}-\mathrm{Zn}$ solutions. The present writer predicted that the solubility would be controlled by the equilibrium reaction:

$$
U Z n_{8.5}(c)=U(s o l)+8.5 Z n(s o l)
$$

\footnotetext{
${ }^{41}$ L. S. Darken, J. Am. Chem. Soc. 72, 2909 (1959).

${ }^{42}$ C. B. Alcock and F. D. Richardson, Acta. Met. 8, 882 (1960).

${ }^{43}$ A. E. Martin and C. Wach, Argonne National Laboratory reports ANL-5996 (1960), ANL-6101 (1960), ANL6477 (1962), ANL-6543 (1962). These are all reports of the CEN Division.

44 J. B. Knighton, R. Tiffany and K. Tobias, Argonne National Laboratory report ANL-7325 (1967).
} 


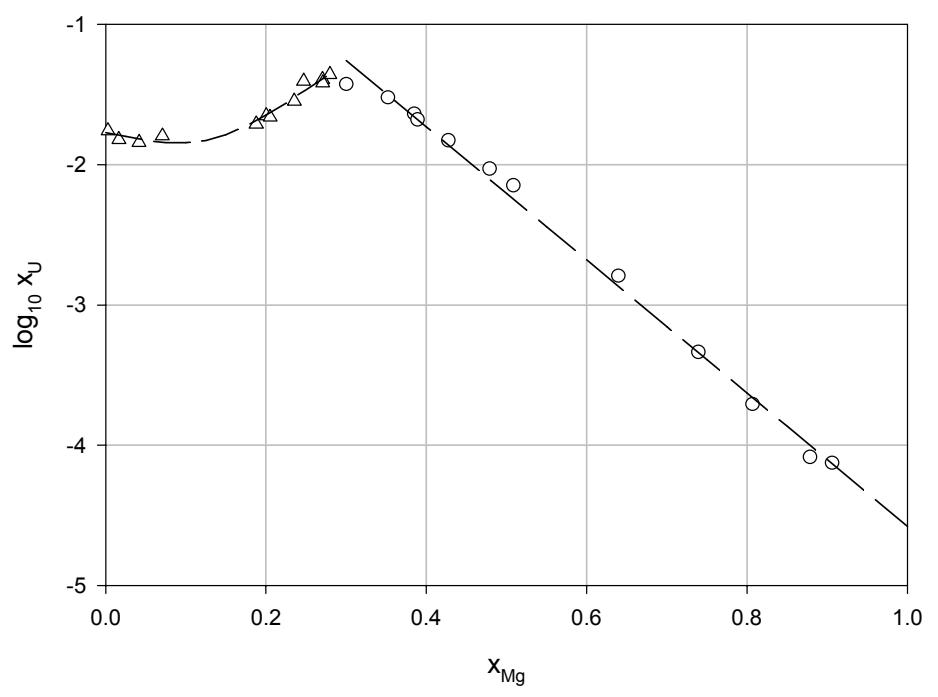

Fig. 4-2. Solubility of Uranium in Liquid Zn-Mg Solutions at $800^{\circ} \mathrm{C}$

$$
\text { ( } \Delta=\text { " } \mathrm{UZn}_{8.5} \text { " solid phase, } \mathrm{o}=\mathrm{U}(\mathrm{s}) \text { solid phase) }
$$

Increasing the $\mathrm{Mg}$ content of the liquid phase would be expected to reduce the $\mathrm{Zn}$ activity and, therefore, drive this reaction to the right and increase the uranium atom fraction. The product of the activity of uranium times the activity of zinc raised to the 8.5 power is constant. This relationship is similar to the "solubility products" found in aqueous solutions of slightly soluble salts. However, Eqs. 4-2 and 4-10 indicate that the addition of Mg might also affect the activity coefficient of $U$ in the liquid solution. We soon realized that this effect might be large since uranium was known to be only slightly soluble in pure magnesium, which would lead to an activity coefficient much greater than unity (about $3.1 \times 10^{4}$ ). The $-\ln \gamma_{U}$ term in Eq. 4-9 would then be less positive ( $\gamma_{U}$ is about 0.14 in pure $\mathrm{Zn}$ at $800^{\circ} \mathrm{C}$ ) and lead to a decrease in the uranium atom fraction. The two effects lead to the solubility decreasing for small additions of $\mathrm{Mg}$, passing through a minimum, and then increasing. We have the classical situation in which, when a minimum (or maximum) is found, two effects are operational, one increases and one decreases the quantity (solubility in this case).

As the $\mathrm{Mg}$ content was increased further, the product of the atom fraction of $U$ and its activity coefficient reached unity, in which case the equilibrium solid phase would change from $\mathrm{UZn}_{8.5}$ to pure solid uranium (the reference phase for uranium). The solubility would then decrease as the $\mathrm{Mg}$ content was further increased because the activity coefficient would continue to increase. The ordinate of the line at the right of the break should then equal the solubility of $U$ in pure liquid $\mathrm{Mg}$ when $\mathrm{x}_{\mathrm{Mg}}=1$. When the early experimental data were examined, we found that the line to the right of the break appeared to approach a solubility value of $U$ at $x_{M g}=1$ that is much less than the solubility of $U$ in pure liquid $\mathrm{Mg}$. Furthermore, the break in the curve was not 
at the correct value of the atom fraction of $\mathrm{Mg}$. While our understanding was still incomplete, the differences between our predictions and the experimental data were too large.

When Martin examined the ingot from the experiment, he found that the uranium phase did not appear to be pure uranium, as had been assumed. He found that this phase was a uranium silicide. The solution had become contaminated with silicon, which was traced to the fused quartz sampling tubes. At the higher $\mathrm{Mg}$ concentrations, the $\mathrm{SiO}_{2}$ was reduced to elemental Si. Martin changed to alumina sampling tubes (tantalum sampling tubes with porous frits had not been developed at this time), and the experimental solubility data then fit the theoretical predictions. Without the theoretical predictions, the experimental artifact due to contamination with silicon may not have been discovered. However, since Martin always made microscopic studies of the cooled ingots from his experiments, he probably would have noted the presence of the silicide. These experiments were done before an electron probe was available, so the routine elemental analysis of phases was not feasible.

Experimental data now exist for the quantities needed to use Eq. 4-9 to compute the solubility of $\mathrm{U}$ in liquid $\mathrm{Zn}-\mathrm{Mg}$ solutions. The Gibbs energy of formation of $\mathrm{UZn}_{8.5}$ and the activity coefficient of $\amalg$ in liquid $\mathrm{Zn}$ can be computed from the results of high-temperature galvanic cell studies. ${ }^{45}$ The solubility of $U$ in liquid $\mathrm{Mg}^{46}$ can be used to estimate the activity coefficient of $U$ in liquid Mg. The D.A.R. correction term, Eq. 4-11 can be computed from the data on the liquid $\mathrm{Zn}-\mathrm{Mg}$ system reported by Chiotti and Stevens.

Unfortunately, the composition for the U-Zn intermetallic phase has not been unambiguously established. Studies by Martin et al. ${ }^{48}$ have established the existence of two or more phases with compositions ranging from about $\mathrm{UZn}_{11}$ to $\mathrm{UZn}_{8.5}$. These compounds appear to differ only slightly in stability, and so it has not been possible to determine exactly the formula of the equilibrium solid phase in the $\mathrm{U}-\mathrm{Zn}$ system as a function of temperature. The galvanic cell studies that ranged from just above the melting point of $\mathrm{Zn}\left(420^{\circ} \mathrm{C}\right)$ to $700^{\circ} \mathrm{C}$ did not indicate significant changes in the equilibrium solid phase. Sharp changes in the temperature dependence of the EMF would have been found if there had been significant changes in the composition of the equilibrium solid phase. To compute the solubility, we have tried values of $\mathrm{n}$ between 8.5 and 12; when the D.A.R approximation for the activity coefficient of $\mathrm{U}$ in the liquid $\mathrm{Zn}-\mathrm{Mg}$ solutions was used, the best agreement between observed and computed solubilities at $800^{\circ} \mathrm{C}$ was obtained with the value of $n$ equal to about 8.53. It is possible that the composition for the equilibrium solid phase depends on the activity of zinc in the liquid phase. Consequently, the value of $n$ that gives the best fit between the experimental and computed solubilities may be an average of the values for the several intermetallics involved. Mason and Chiotti ${ }^{49}$ have explained how the substitution of pairs of zinc atoms in a basic $\mathrm{UZn}_{12}$ structure can account for the variation in composition found experimentally.

\footnotetext{
45 These studies have only been briefly reported in a paper presented at an International Atomic Energy Agency symposium in 1962; a complete paper has never been published.

${ }^{46}$ P. Chiotti and H. E. Shoemaker, Ind. Eng. Chem. 50, 137 (1958).

${ }^{47}$ P. Chiotti and E. R. Stevens, Trans. Met. Soc. AIME 233, 198 (1965).

${ }^{48}$ A. E. Martin, R. S. Schablaske, and N. Stalica, Argonne National Laboratory, private communication (1965).

49 J. T. Mason and P. Chiotti, Acta Cryst. B27, 1789 (1967).
} 
The results of computations of the solubility of $\mathrm{U}$ in liquid $\mathrm{Zn}-\mathrm{Mg}$ solutions at $800^{\circ} \mathrm{C}$ are shown in Fig. 4-3. This figure shows that the agreement between the observed and computed values of the solubility when " $\mathrm{UZn}_{8.5}$ " is the equilibrium phase is satisfactory for $\mathrm{n}=8.53$. The greatest differences between observed and computed values are in the regions of the minimum and the maximum. The difference in the region of the minimum is probably caused by the use of $\mathrm{n}$ too small for the region of highest $\mathrm{Zn}$ activities. The scatter of the experimental data, perhaps due to a lack of equilibrium between the solid and the solution, makes a meaningful computation based on several values for $n$ impossible. The difference in the region of the maximum is due to the fact that the D.A.R. approximation for the activity coefficient of uranium does not take into account any dependence of the activity coefficient on the concentration of uranium in the solution. There is a factor of three difference in concentration between the solubility in pure zinc and the maximum solubility. The data obtained from our high-temperature cells did not allow the concentration dependence of the activity coefficient to be determined in pure liquid zinc. Darken, ${ }_{\text {Wafking sufficient data on the ternary system to apply the exact quadratic formalism of }}$ place of Eqs. 4-10 and 4-11 the activity coefficient of $\mathrm{U}$ in the liquid $\mathrm{Zn}-\mathrm{Mg}$ is given by the equation:

$$
\ln \gamma_{U}=a+b x_{M g}+c x_{U}
$$

where a, b, and c are similar to Wagner's "interaction parameters," which are temperature dependent. The values of $a, b$, and $c$ were estimated from the activity coefficients computed from the solubilities, where pure solid $U$ was the equilibrium phase, and the activity coefficient was obtained for the pure liquid zinc system from the EMF data. It was found that $\mathrm{a}=-1.0049, \mathrm{~b}=$ 5.816 , and $\mathrm{c}=18.092$. The $\left(a+b x_{M g}\right)$ term should be approximately equal to the geometric mean activity coefficient expression (Eq. 4-10). If the activity coefficients in pure $\mathrm{Zn}$ and $\mathrm{Mg}$ are used, then $\mathrm{a}=-0.857$ and $\mathrm{b}=5.641$. Thus, Eq. 4-14 is similar to Eq. 4-10, with the "correction term" given by $c x_{U}$. If the activity coefficient of $U$ in the liquid $\mathrm{Zn}-\mathrm{Mg}$ is computed from Eq. 4-14, the observed and calculated solubilities agree quite well, as shown in Fig. 4-4. In this case, the best fit was obtained if intermetallic composition was assumed to be $\mathrm{UZn}_{10.175}$.

An attempt was made to replace the formalism suggested by St. Pierre et al. ${ }^{52}$ with the interaction parameter formalism, but the concentration of uranium in the solutions over part of the composition range was too large. Apparently, the U-U interactions when the concentrations exceed 0.01 mole fraction are sufficient to require a more complicated treatment.

\footnotetext{
${ }^{50}$ L.S. Darken, Trans. Met. Soc. AIME 239, 90 (1967).

${ }^{51}$ C. Wagner, Thermodynamics of Alloys, Addison-Wesley, Cambridge, MA, pp. 51-53 (1952).

52 G. R. St. Pierre, H. A. Holla, and K. V. Gourishankar, In Proceedings of the Ethem T. Turkdogan Symposium, Iron and Steel Society, pp. 125-139 (1994).
} 


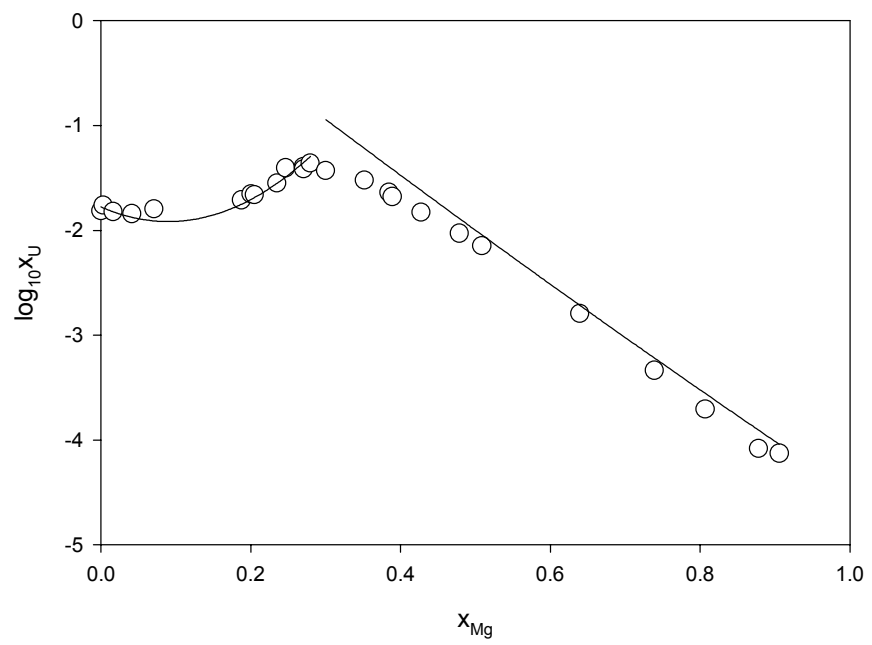

Fig. 4-3. Observed (circles) and Computed (solid line) Solubility of Uranium in Liquid $\mathrm{Zn}-\mathrm{Mg}$ at $800^{\circ} \mathrm{C}$. Computed curve obtained with $\mathrm{n}=8.53$ for " $U Z \mathrm{n}_{8.5}$ " phase and D.A.R. estimate used for the activity coefficient of $\mathrm{U}$ in the liquid $\mathrm{Zn}-\mathrm{Mg}$ solution.

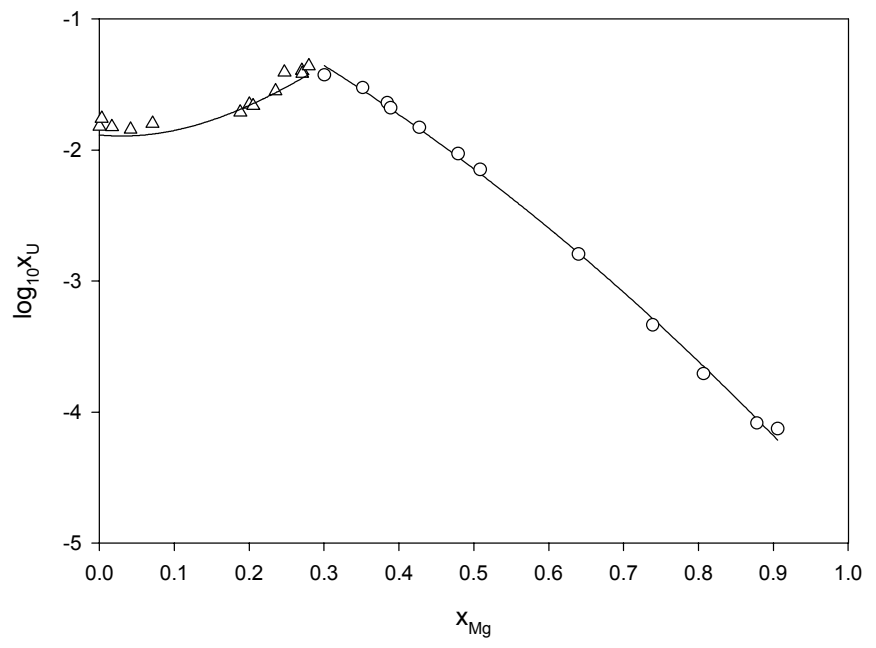

Fig. 4.4. Observed (circles) and Computed (solid line) Solubility of $U$ in liquid $\mathrm{Zn}-\mathrm{Mg}$ at $800^{\circ} \mathrm{C}$. Calculated values obtained using "interaction parameter" for the $\mathrm{U}$ activity coefficient and $\mathrm{n}=$ 10.175 in " $\mathrm{UZn}_{8.5}$. " 


\section{Phase Rule}

The Gibbs phase rule (the same Willard Gibbs that brought us the "Gibbs" free energy, ca. 1876) is

$$
F=C-P+2
$$

where $\mathrm{F}$ is the degrees of freedom, $\mathrm{C}$ is the number of components, and $\mathrm{P}$ is the number of phases. The degrees of freedom are the number of quantities that must be specified to fix the system, or stated another way, the number of variables. For a one-component system (for example, water), the maximum number of phases possible is three. A mixture of liquid water, ice, and water vapor has no degrees of freedom. The value of the vapor pressure is fixed, as is the temperature. Such a system (water in a sealed tube with no other gases) is used as a temperature standard, i.e., a triple-point temperature standard. Next, consider a system composed of two components, e.g., $\mathrm{U}$ and $\mathrm{Cd}$. If there is one liquid solution, one solid phase, and one gas phase in equilibrium, the system will have one degree of freedom. If the value of the temperature is set, the composition of the two condensed phases (liquid and solid) as well as the vapor pressure will be fixed.

We are interested in the ternary system of $\mathrm{U}, \mathrm{Pd}$, and $\mathrm{Cd}$ in the next example. So we have three components, and the number of degrees of freedom will vary from three to one as the number of solid phases is varied from zero to two. We assume that there will always be one vapor and one liquid solution phase. If we are measuring "solubility," there will always be at least one solute-rich phase (solid), so we will start out with two degrees of freedom. Thus, if we set the value of the temperature, we must also set the value of some other variable. This can be the composition of the liquid solution. This reasoning agrees with what would be expected, i.e., the solubility of a solid in a liquid is dependent of the composition of the "solvent," where a mixture of two of the components is assumed to be the solvent.

Note that the phase rule does not give any information on the composition of the solid phase. The phase rule indicates that a solid of a given composition has only one liquid composition that is in equilibrium at a given temperature. The phase rule does not yield any information on the numerical values of the compositions. The phase rule is based on exact thermodynamic relations and is not dependent on assumptions regarding molecular speciation, crystal structure, etc. It is recommended that the reader review the derivation of the phase rule in a physical chemical or thermodynamics textbook. Its use greatly simplifies the consideration of heterogeneous equilibria. The mathematics requires only the ability to count.

We next present an example of the equilibria that can exist when two solutes interact to form a binary compound, This example is taken from the experimental work of Milt Ader ${ }^{53}$ as well as Karl Anderson. ${ }^{54}$

\footnotetext{
${ }^{53}$ Milt Ader, Chemical Engineering Division, Argonne National Laboratory, unpublished information (1959).

${ }^{54}$ Karl Anderson, Chemical Engineering Division, Argonne National Laboratory, unpublished information (1962).
} 
Ader found that when he added (dissolved) palladium to a saturated solution of uranium in liquid cadmium, the uranium solubility was markedly decreased from the values found for the binary U-Cd system. Recall that the solid phase in equilibrium with a liquid U-Cd is either the $\mathrm{UCd}_{11}$ intermetallic or pure U. Dissolving Pd in the liquid phase would be expected to change the activity coefficient of $U$ in the solution and, therefore, change the "solubility." Relatively small additions of $\mathrm{Pd}$ would be expected to make only small changes in the activity coefficient and hence only small changes in the solubility. However, Ader found that the solubility, i.e., the U content of the liquid phase, decreased by one to two orders of magnitude from the values in the binary U-Cd system. The solubilities of $\mathrm{U}$ in liquid $\mathrm{Cd}$ to which $\mathrm{Pd}$ has been added and in liquid $\mathrm{Cd}$ alone are compared in Fig. 4-5 as a function of reciprocal temperature. The large effect of $\mathrm{Pd}$ on the solubility of $U$ is seen.

In these experiments, Milt Ader started with about $1190 \mathrm{~g}$ of a $2 \% \mathrm{U}-\mathrm{Cd}$ solution to which he added $82 \mathrm{~g}$ of $\mathrm{Pd}$. The initial composition was $1.9 \% \mathrm{U}$ and $6.45 \% \mathrm{Pd}$. The system was held at $579^{\circ} \mathrm{C}$ (probably over night), and a filtered sample of the liquid phase taken. The sample was found to contain $0.94 \% \mathrm{U}$ and $6.86 \% \mathrm{Pd}$. These concentrations make sense if it is assumed that the uranium had been precipitated as the $\mathrm{UPd}_{3}$ intermetallic compound, and that a significant amount of the $\mathrm{Cd}$ had been vaporized from the system. The vaporization is not unreasonable since the vapor pressure of liquid cadmium is about $0.1 \mathrm{~atm}$ at $579^{\circ} \mathrm{C}$. The top flange of the solubility apparatus was water cooled to protect its O-ring seal and, therefore, acted as a condenser. At the time of these experiments, an electron probe was not available to examine the ingot and so the composition of the U-rich phase could not be determined. Attempts by Ader to leach the cadmium from the U-rich phase using aqueous $\mathrm{NH}_{4} \mathrm{NO}_{3}$ did not yield a residue that could be identified using x-ray diffraction.

At the time of Ader's experiments, there were no data for the thermodynamics of the various U-Pd intermetallic compounds. Thus, all that could be shown was that his data were consistent with the assumption that the U-rich phase was the $\mathrm{UPd}_{3}$ intermetallic. Since Ader's experiments, Kleykamp ${ }^{55}$ has critically reviewed the thermodynamic data on intermetallic compounds between the various transition element metals. His review included the various actinide transition metal compounds. A more complete analysis of Ader's data can now be made.

It is assumed that the solubility equilibrium reaction can be written

$$
U P d_{3}(c)=U(\text { liq } C d)+3 P d(l i q C d)
$$

where liq $C d$ indicates in solution in the liquid $\mathrm{Cd}$. The solubility equilibrium relation is

$$
a_{U} a_{P d}^{3}=K_{a}=\exp \left(\frac{-\Delta_{r} G^{o}}{R T}\right)
$$

where the $a$ 's are activities, and $\Delta_{\mathrm{r}} \mathrm{G}^{0}$ is the standard Gibbs energy of the above reaction.

\footnotetext{
${ }^{55}$ H. Kleykamp, "Thermodynamics of the Systems of the Platinum Metals with other Transition Metals: I. Integral Data," Proc. of $47^{\text {th }}$ Calorimetry Conf., August 16-21, 1992, Snowbird, UT (1992)
} 
If the product of the mole fractions and the activity coefficients replaces the activities, then the following relation is obtained:

$$
\log \left(x_{u} x_{P d}^{3}\right)=\frac{-\Delta_{r} G^{o}-G_{U}^{x s}-3 G_{P d}^{x s}}{2.3 R T}
$$

where the excess Gibbs energies are given by RT( $\left.\ln \gamma_{\mathrm{U}}\right)$ or $\mathrm{RT}\left(\ln \gamma_{\mathrm{Pd}}\right)$. Since all of the Gibbs energies can be replaced by $\Delta \mathrm{H}-\mathrm{T} \Delta \mathrm{S}$, a plot of the left hand side of Eq. 4-18 vs. the reciprocal of the absolute temperature should yield a straight line, whose slope is equal to a combination of enthalpies. This assumes that the enthalpies and entropies are not strong functions of the temperature. Ader's data were used to prepare Fig. 4-6. It is seen that a straight line is obtained when the solid phase is assumed to be $\mathrm{UPd}_{3}$. The "solubility product" is the left-hand side of Eq. 4-18. Other assumptions about the stiochiometry of the solid phase gave curved lines.

Since the Gibbs energy of formation of $\mathrm{UPd}_{3}$ is known, and the excess Gibbs energy of $U$ in the liquid $\mathrm{Cd}$ solution can be estimated from the data for the U-Cd system, the excess Gibbs energy of Pd dissolved in liquid $\mathrm{Cd}$ can be computed. The results are shown in Fig. 4-7. This example illustrates the utility of the thermodynamic treatment.

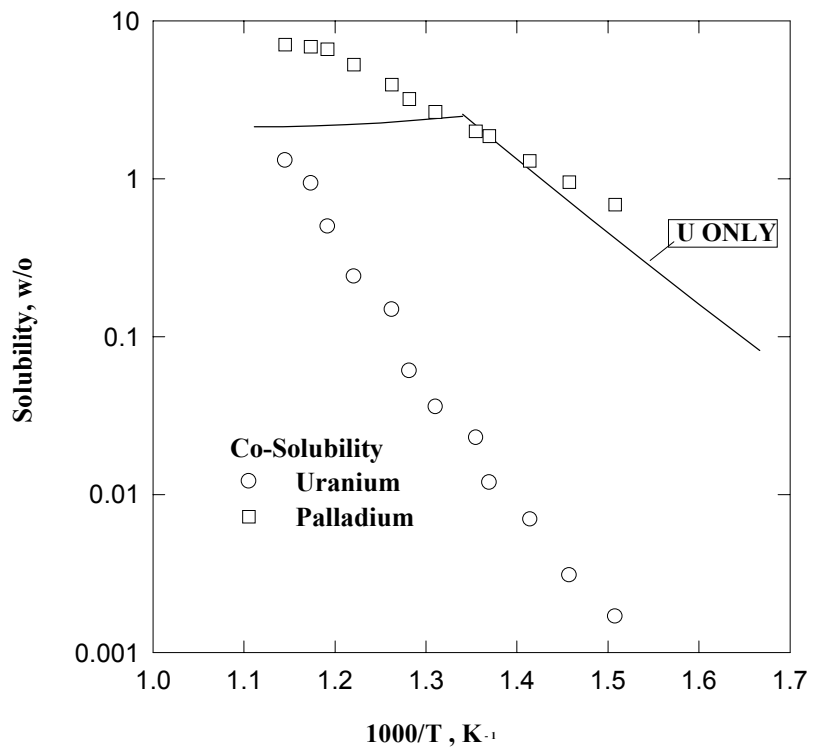

Fig. 4-5. Effect of Pd on the Solubility of $U$ in Liquid Cd. Data from M. Ader. ${ }^{53}$ 


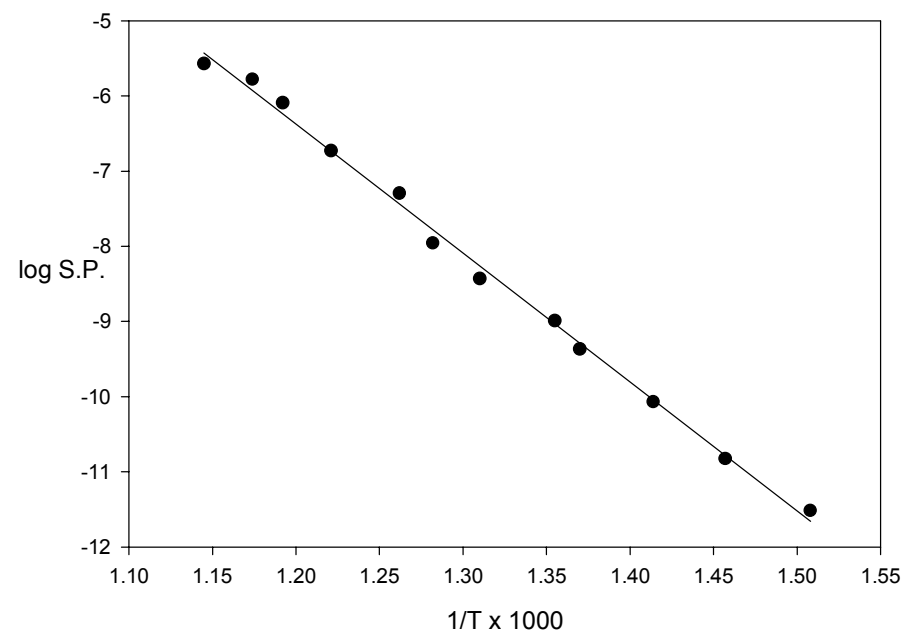

Fig. 4-6. Solubility Product (S.P.) of $\mathrm{UPd}_{3}$ Dissolved in Liquid Cd. Data from M. Ader. ${ }^{53}$

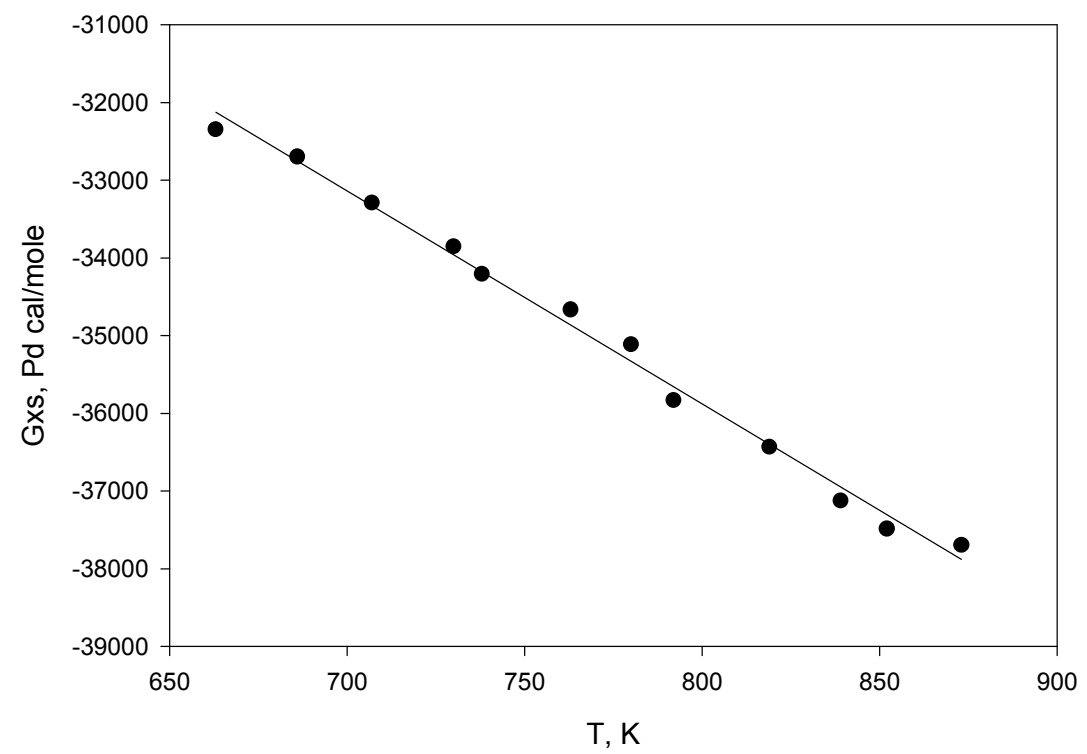

Fig. 4-7. Excess Gibbs Energy of Pd Dissolved in Liquid Cadmium. Computed from Ader's data ${ }^{53}$ for the co-solubility of U and Pd. 


\section{E. Effects of Co-precipitation}

Co-precipitation is being introduced in this section on metallic systems because it has been of special importance to the development of processes in which intermetallic phases are involved. Early in the development of processes based on the formation of solid intermetallic phases in liquid metal solutions, we found that under some conditions, the solid carried from the solution small amounts of metals not part of the pure intermetallic compound. This phenomenon is known as "co-precipitation." It is also of importance to zone refining and coring in metallic ingots. In the terminology of co-precipitation, the impurity is referred to as the tracer, and the precipitating phase, the carrier.

From aqueous solution, co-precipitation may occur as a result of adsorption on the surface of the carrier, occlusion of the liquid within the crystal, or formation of a solid solution of the tracer in the carrier. In liquid metal systems, it is relatively easy to form large regular crystals of the carrier. Also, the effects of adsorption and occlusion may be minimized, and the influence of substitutional solid-solution formation made to predominate. Previous studies of the crystallization of some intermetallic compounds ${ }^{56}$ have shown that the co-precipitation or partition behavior of trace metals is analogous to that in aqueous systems when ionic substitution occurs, e.g., co-precipitation of $\mathrm{Ra}^{2+}$ with $\mathrm{BaSO}_{4}$. Recall that the first person to identify and synthesize plutonium, Glenn Seaborg, used co-precipitation to study its chemistry when only trace amounts were available, and the first process for the recovery of plutonium was based on co-precipitation. In additon, the Curies used co-precipitation in their discoveries of Po and Ra.

John Moriarty ${ }^{39}$ made a systematic study of co-precipitation in liquid metal solutions. He prepared a slightly undersaturated solution of the carrier in liquid cadmium to which he added tracer. The concentration of the tracer was always so low that saturation over the entire temperature range investigated was never exceeded. The solution was cooled in a stepwise fashion. After each step, a portion of the carrier precipitated, and a sample of the supernatant solution was taken for analysis. Most of the experiments were done using $\mathrm{Ce}$ as the carrier. The precipitate was the intermetallic compound $\mathrm{CeCd}_{11}$. The data from a typical experiment are given in Table 4-2. In this experiment the carrier was $\mathrm{CeCd}_{11}$ and the tracer $\mathrm{Pr}$, which was added as radioactive ${ }^{142} \operatorname{Pr}$ (prepared using the $\mathrm{CP}-5$ reactor at Argonne).

Depending on the model used, one can treat the results from these experiments by two methods, homogeneous or logarithmic co-precipitation. Homogeneous co-precipitation occurs when the tracer partitions at all times in an equilibrium fashion between the solution and the total precipitate. The co-precipitation coefficient, $\mathrm{D}$, is computed using the following relation:

$$
\left(\frac{B}{A}\right)_{\text {entire crystal }}=D\left(\frac{B}{A}\right)_{\text {solution }}
$$

\footnotetext{
${ }^{56}$ H. M. Feder and R. J. Teitel, "Purification of Reactor Fuels and Blankets by Crystallization from Liquid Metal Solvents," Atomic Energy Conference Proceedings, Geneva, 17, 303-400 (1958).
} 
where $A$ and $B$ represent concentrations of carrier and tracer, respectively. Using the data in Table 4.1 for $479^{\circ} \mathrm{C}$, we computed $\mathrm{D}$ as follows:

$$
D=\frac{\left(\frac{0.329}{0.452}\right)}{\left(\frac{0.671}{0.548}\right)}=\frac{0.728}{1.224}=0.594
$$

Values of D computed in this way are shown in the fifth column of Table 4-2. The data indicate that the $\mathrm{D}$ values slowly decrease as more $\mathrm{CeCd}_{11}$ precipitate is formed.

Table 4-2. Co-precipitation of Pr with Ce from Cd Solution.

Coefficients in last two columns defined in Secs. II and III.

\begin{tabular}{|c|c|c|c|c|}
\hline $\mathrm{T},{ }^{\circ} \mathrm{C}$ & Fraction Ce, soln & Fraction Pr, soln & $\lambda$ & $\mathrm{D}$ \\
\hline 505 & 1.000 & 1.000 & -- & -- \\
\hline 479 & 0.548 & 0.671 & 0.663 & 0.594 \\
\hline 455 & 0.310 & 0.456 & 0.670 & 0.536 \\
\hline 427 & 0.155 & 0.290 & 0.664 & 0.449 \\
\hline 397 & 0.0620 & 0.168 & 0.642 & 0.327 \\
\hline 374 & 0.0322 & 0.111 & 0.640 & 0.266 \\
\hline 348 & 0.0131 & 0.0664 & 0.626 & 0.187 \\
\hline
\end{tabular}

Logarithmic co-precipitation occurs when the tracer partitions with a constant distribution between the solution and only the precipitate that is being formed at any instant. This relation was described by Doerner and Hoskins $\stackrel{\text { [7] }}{ }$.

$$
\log \left(\frac{B_{o}}{B_{f}}\right)_{\text {solution }}=\lambda \log \left(\frac{A_{o}}{A_{f}}\right)_{\text {solution }}
$$

where the subscripts o and $f$ denote initial and final, and $\lambda$ is the co-precipitation coefficient. For $479^{\circ} \mathrm{C}, \lambda$ is the following value:

\footnotetext{
${ }^{57}$ H. Doerner and W. Hoskins, J. Am. Chem. Soc. 47, 662 (1925)
} 


$$
\lambda=\frac{\log \left(\frac{1.000}{0.671}\right)}{\log \left(\frac{1.000}{0.548}\right)}=\frac{0.173}{0.261}=0.663
$$

The fourth column of Table 4-2 gives $\lambda$ values for other temperatures. These values are nearly constant for the various stages of the precipitation. The precipitated $\mathrm{CeCd}_{11}$ can be compared to an onion, with layers of gradually decreasing contents of the tracer as the surface is approached. A plot of the logarithm of the fraction of tracer in the solution $v s$. the logarithm of the fraction of carrier in the solution gives a straight line, whose slope is the co-precipitation coefficient. The data in Table 4-2 are plotted in Fig. 4-8.

Moriarty's data ${ }^{39}$ indicate that the value of the co-precipitation coefficient depends on the similarity of the crystal structure of the carrier and tracer. When the carrier and tracer form solids with the same crystal structures, the co-precipitation coefficient can be expected to be greater than zero. On the other hand, when the crystal structures are different, co-precipitation is expected to be very small. When the carrier and tracer formed the same crystal structure, the coprecipitation coefficient was smaller the greater the solubility of the tracer relative to the carrier. This is shown in Fig. 4-9, where the co-precipitation coefficient is plotted $v s$. the ratio of the solubility of the carrier to the solubility of the tracer $\left(\right.$ at $400^{\circ} \mathrm{C}$ ). The single element names refer to co-precipitation by $\mathrm{CeCd}_{11}$ as the carrier. Two points which refer to co-precipitation of $\mathrm{Ce}$ as the tracer on either $\mathrm{LaCd}_{11}$ or $\mathrm{UCd}_{11}$ as the carriers are also shown. In all cases the carrier precipitate and the tracer have the same crystal structures. As can be seen in Fig. 4-9, all of the points fall on a smooth curve. This curve indicates that the greater the solubility of the tracer in the solution, the less the tendency to co-precipitate.

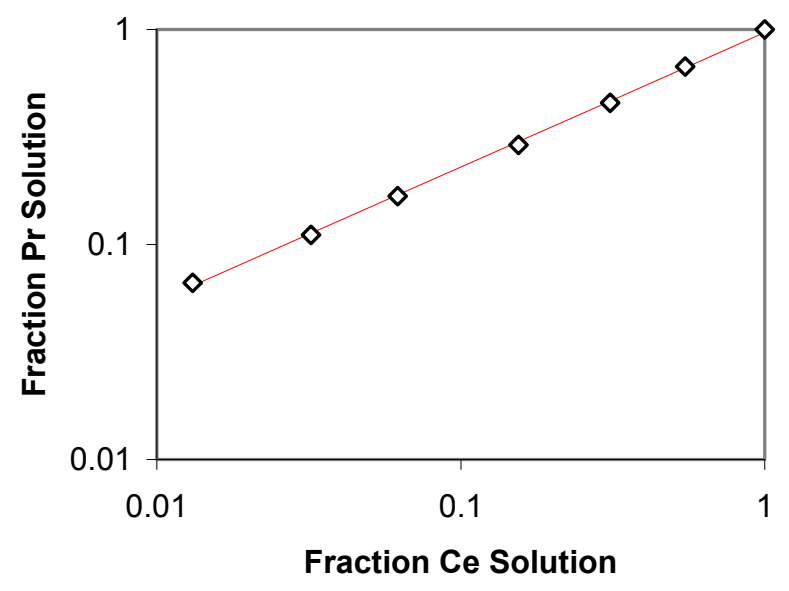

Fig. 4-8. Co-precipitation of $\mathrm{Pr}$ from Liquid $\mathrm{Cd}$ Solution by $\mathrm{CeCd}_{11}$. Data from Moriarty. ${ }^{39}$ 


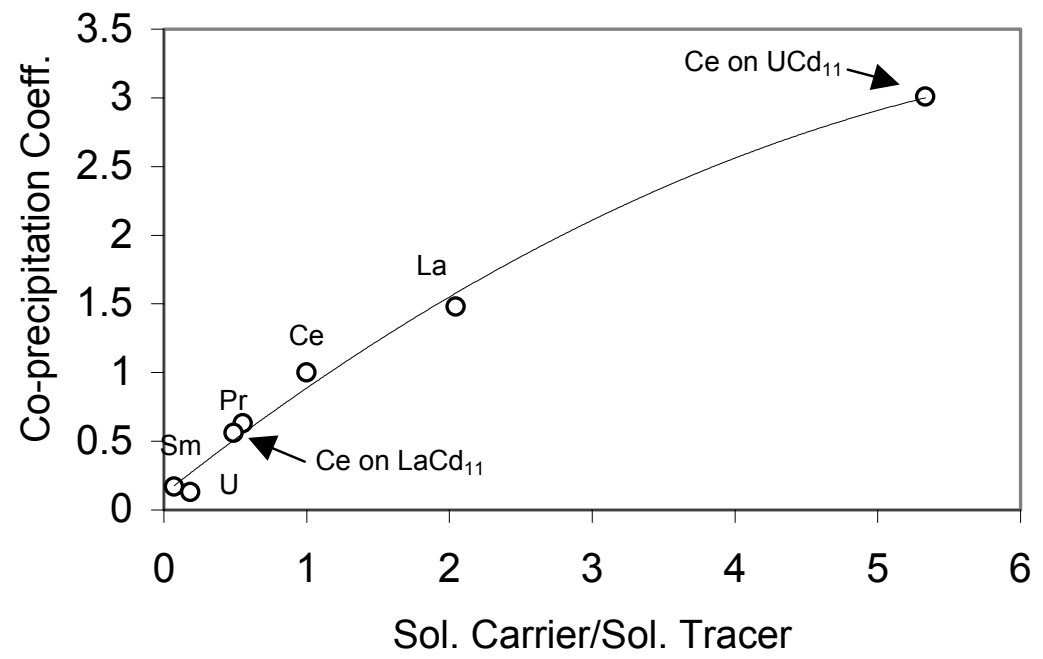

Fig. 4-9. Relation of Co-precipitation Coefficient to Ratio of Solubilities of Carrier and Tracer at $400^{\circ} \mathrm{C}$. All solutes form the same $\mathrm{MCd}_{11}$ intermetallic phase.

\section{ACKNOWLEDGMENTS}

This report is being published posthumously as a tribute to Dr. Johnson's many contributions to the understanding of pyrochemical processes through thermodynamic analysis. 


\section{Distribution List for ANL-01/16}

Internal:

D. P. Abraham

J. P. Ackerman

R. K. Ahluwalia

J. K. Basco

D. Baurac

R. W. Benedict

R. J. Blaskovitz

D. J. Chaiko

Y. I. Chang

L. S. H. Chow

T. H. Fanning

J. K. Fink
A. A. Frigo

E. C. Gay (25)

K. M. Goff

K. V. Gourishankar

J. E. Harmon (2)

M. C. Hash

A. S. Hebden

J. E. Herceg

J. J. Laidler

L. Leibowitz

D. Lewis

M. A. Lewis
D. Lexa

A. A. Leyva

P. Lysenko

V. A. Maroni

S. M. McDeavitt

W. E. Miller

L. R. Morss

M. K. Richmann

C. T. Snyder

M. A. Williamson

J. L. Willit

TIS Files

\section{External:}

DOE-OSTI

ANL-E-Library

ANL-W-Library

Chemical Technology Division Review Committee Members:

H. U. Anderson, University of Missouri-Rolla, Rolla, MO

A. L. Bement, Jr., Purdue University, West Lafayette, IN

R. A. Greenkorn, Purdue University, West Lafayette, IN

C. L. Hussey, University of Mississippi, University, MS

M. V. Koch, University of Washington, Seattle, WA

V. P. Roan, Jr., University of Florida, Gainesville, FL

J. R. Selman, Illinois Institute of Technology, Chicago, IL

J. S. Tulenko, University of Florida, Gainesville, FL

J. E. Battles, Oak Forest, IL

L. Burris, Naperville, IL

A. K. Fischer, Western Springs, IL

C. E. Johnson, Elk Grove Village, IL

T. R. Johnson, Wheaton, IL

E. J. Karell, Pleasant Hills, PA

N. Levitz, Chicago, IL

C. C. McPheeters, Naperville, IL

P. A. G. O'Hare, Darien, IL

R. A. Osteryoung, North Carolina State University, Raleigh, NC

R. D. Pierce, Naperville, IL

J. L. Settle, Plainfield, IL

M. J. Steindler, Downers Grove, IL

R. K. Steunenberg, Naperville, IL (25)

Z. Tomczuk, Lockport, IL 
